\title{
SNAP-25 Is a Target of Protein Kinase C Phosphorylation Critical to NMDA Receptor Trafficking
}

\author{
C. Geoffrey Lau, ${ }^{1}$ Yukihiro Takayasu, ${ }^{1}$ Alma Rodenas-Ruano, ${ }^{1}$ Ana V. Paternain, ${ }^{2}$ Juan Lerma, ${ }^{2}$ Michael V. L. Bennett, ${ }^{1}$ \\ and R. Suzanne Zukin ${ }^{1}$ \\ ${ }^{1}$ Rose F. Kennedy Center, Dominick P. Purpura Department of Neuroscience, Albert Einstein College of Medicine, Bronx, New York 10461, and 2Instituto \\ de Neurociencias de Alicante, Consejo Superior de Investigaciones Científicas-Universidad Miguel Hernández, 03550 San Juan de Alicante, Spain
}

Protein kinase C (PKC) enhances NMDA receptor (NMDAR)-mediated currents and promotes NMDAR delivery to the cell surface via SNARE-dependent exocytosis. Although the mechanisms of PKC potentiation are established, the molecular target of PKC is unclear. Here we show that synaptosomal-associated protein of $25 \mathrm{kDa}$ (SNAP-25), a SNARE protein, is functionally relevant to PKC-dependent NMDAR insertion, and identify serine residue- 187 as the molecular target of PKC phosphorylation. Constitutively active PKC delivered via the patch pipette potentiated NMDA (but not AMPA) whole-cell currents in hippocampal neurons. Expression of RNAi targeting SNAP-25 or mutant SNAP-25(S187A) and/or acute disruption of the SNARE complex by treatment with BoNT A, BoNT B or SNAP-25 C-terminal blocking peptide abolished NMDAR potentiation. A SNAP-25 peptide and function-blocking antibody suppressed PKC potentiation of NMDA EPSCs at mossy fiber-CA3 synapses. These findings identify SNAP-25 as the target of PKC phosphorylation critical to PKC-dependent incorporation of synaptic NMDARs and document a postsynaptic action of this major SNARE protein relevant to synaptic plasticity.

\section{Introduction}

NMDARs are glutamate-gated ion channels and play a pivotal role in the regulation of synaptic function in the brain. NMDARs are heteromeric assemblies of NR1, NR2, and NR3 subunits, which cotranslationally assemble in the endoplasmic reticulum (ER) to form functional channels with differing physiological and pharmacological properties (Wenthold et al., 2003; Pérez-Otaño and Ehlers, 2005; Lau and Zukin, 2007). NMDAR-mediated $\mathrm{Ca}^{2+}$ influx is essential for synaptogenesis, experience-dependent synaptic remodeling, and long-lasting changes in synaptic efficacy such as long-term potentiation (LTP) and depression (LTD), cellular processes widely believed to underlie learning and memory (Collingridge et al., 2004; Malenka and Bear, 2004). Recent studies indicate that NMDARs serve not only as a trigger

Received 0ct. 13, 2008; revised Aug. 17, 2009; accepted 0ct. 27, 2009.

This work was supported by National Institutes of Health Grants NS20752 (to R.S.Z.), NS45287 (to M.V.L.B.), and BFU2006-007138 (to J.L.). M.V.L.B. is the Sylvia and Robert S. Olnick Professor of Neuroscience and Distinguished Professor of the College. We thank Drs. Robert J. Wenthold, Michael D. Ehlers, Pablo E. Castillo, Reed C. Carroll, and Leonard K. Kaczmarek for helpful scientific discussions, and Adrianna Latuszek, Yingjia Liu, Roodie Regis, and Judy Wong for excellent technical assistance. We thank Drs. Masayoshi Mishina (University of Tokyo, Tokyo, Japan), Shigetada Nakanishi (Kyoto University, Kyoto, Japan), and Stefano Vicini (Georgetown University Medical Center, Washington, DC) for NR1 and NR2 CDNAs, and Masami Takahashi (Kitasato University, Kitasato, Japan) for the generous gift of the phospho-SNAP-25 antibody.

Correspondence should be addressed to Dr. R. Suzanne Zukin, Dominick P. Purpura Department of Neuroscience, Kennedy Center Room 602B, Albert Einstein College of Medicine, 1300 Morris Park Avenue, Bronx, NY 10461. E-mail: suzanne.zukin@einstein.yu.edu.

C. G. Lau's present address: Department of Molecular and Cellular Biology and Center for Brain Science, Harvard University, 16 Divinity Avenue, Cambridge, MA 02138.

Y. Takayasu's present address: Department of Otolaryngology, Gunma University Graduate School of Medicine, 3-39-22 Showa-machi, Maebashi, Gunma 371-8511, Japan.

DOI:10.1523/JNEUROSCI.4933-08.2010

Copyright $\odot 2010$ the authors $\quad 0270-6474 / 10 / 300242-13 \$ 15.00 / 0$ of synaptic plasticity, but may also contribute to the expression of LTP and LTD (Lau and Zukin, 2007).

PKC plays a critical role in memory formation and storage (Wang et al., 2006), induction of LTP (Ben-Ari et al., 1992), and vesicular exocytosis (Morgan et al., 2005). PKC increases NMDAR channel opening rate in Xenopus oocytes and promotes NMDAR insertion at the cell surface via SNARE-dependent exocytosis (Lan et al., 2001a). PKC phosphorylates NR1 at Ser890 and Ser896 near an RXR ER retention motif and promotes NMDAR forward trafficking (Scott et al., 2001, 2003). Although NMDARs are a known functional target of PKC potentiation, the direct molecular target of $\mathrm{PKC}$ phosphorylation is unclear. Target PKC and PKA phosphorylation sites have been identified on the NR1, NR2A, and NR2B subunits (Leonard and Hell, 1997; Tingley et al., 1997). However, NMDARs assembled from mutant subunits lacking all known sites of PKC phosphorylation show marked PKC potentiation (Zheng et al., 1999; but see Liao et al., 2001), suggesting that the molecular target of PKC is a receptor-associated signaling and/or trafficking protein.

Emerging evidence indicates a role for the SNARE family of membrane fusion proteins in trafficking of postsynaptic glutamate receptors (Lledo et al., 1998; Lan et al., 2001a; Lu et al., 2001; Washbourne et al., 2004). The synaptosomal-associated protein of $25 \mathrm{kDa}$ (SNAP-25) is a member of the SNARE family and a known target of PKC phosphorylation (Shimazaki et al., 1996). SNAP-25 assembles with syntaxin-1 and vesicle-associated membrane protein-2 (VAMP2/synaptobrevin-2) via SNARE motifs to form the SNARE complex, the minimal machinery necessary for exocytosis of neurotransmitter vesicles at the presynaptic terminal (Jahn et al., 2003). SNAP-25, syntaxin-1, and VAMP2 localize 
to biochemical fractions of postsynaptic densities (PSDs), consistent with the possibility that they also participate in trafficking of postsynaptic receptors (Jordan et al., 2004; Cheng et al., 2006).

The present study was undertaken to identify the molecular target of PKC phosphorylation functionally relevant to PKCinduced insertion of NMDARs at the cell surface of neurons. SNAP-25 is implicated in vesicular fusion and/or docking at presynaptic terminals (Washbourne et al., 2002a) and PKC phosphorylation of Ser187 in SNAP-25 is important to vesicular recruitment in adrenal chromaffin cells (Nagy et al., 2002). Here we show that PKC phosphorylation of SNAP-25 at Ser187 is critical to PKC-induced, SNARE-dependent insertion of NMDARs at synaptic sites, a mechanism relevant to synaptic plasticity.

\section{Materials and Methods}

DNA constructs. NR $1_{100}$ (NR1-4b) and NR2A cDNAs in pBluescript SK $(-)$ vector were linearized at the $3^{\prime}$ end with BamHI and NotI, respectively, and used for in vitro transcription of mRNA. WT and $\Delta 20$ (dominant-negative) mutant constructs of SNAP-25 in pcDNA3 were gifts from Dr. Roger Y. Tsien (Howard Hughes Medical Institute, University of California, San Diego, CA). SNAP-25 constructs were linearized at the $3^{\prime}$ end with EcoRI. Capped mRNAs were synthesized as runoff transcripts from linearized plasmid cDNAs with T7 polymerase (mMessage mMachine transcription kit; Ambion; $2 \mathrm{~h}$ at $37^{\circ} \mathrm{C}$ ).

Mutagenesis. The SNAP-25 protein sequence harbors 3 sites that conform to the PKC consensus phosphorylation motif (S/T-X-R/K): Ser28, Thr29 and Ser187. These residues in SNAP-25 were mutated into Ala or Asp by site-directed mutagenesis, singly or altogether using the QuikChange XL Site-Directed Mutagenesis Kit according to the manufacturer's protocol (Stratagene). The mutagenic primer sequences for the S187A mutation were $\left(5^{\prime}\right.$ to $\left.3^{\prime}\right)$ : GATCATGGAGAAGGCTGACGCCAACAAAACCAGAATTG and CAATTCTGGTTTTGTTGGCGTCAGC CTTCTCCATGATC; for S187D were GATCATGGAGAAGGCTGACGACAACAAAACCAGAATT GATG and CATCAATTCTGGTTTTGTTGTCGTCAGCCTTCTCCATGATC; for S28AT29A were GGCTGATGAGTCCCTCGAGGCCGCCCGTCGCATGCTGC and GCAGCATGCGACGGGCGGC CTCGAGGGACTCATCAGCC. Introduction of an XhoI site (underlined) in the S28AT29A primers allowed fast screening of the mutant by restriction digest.

Subcloning. For transfection into HEK-293 cells and neurons in culture, WT and mutant SNAP-25 cDNAs were subcloned into the pIRES2EGFP vector (BD Biosciences Clontech), which allows production of a single bicistronic mRNA containing SNAP-25 and EGFP. SNAP-25 cDNAs were excised from pcDNA3 with BamHI ( $\left.5^{\prime}\right)$ and EcoRI ( $\left.3^{\prime}\right)$, and pIRES2-EGFP was cut with BglII ( $\left.5^{\prime}\right)$ and EcoRI $\left(3^{\prime}\right)$ enzymes and the $5^{\prime}$ end dephosphorylated by CIAP. The fragments were ligated together overnight at $16^{\circ} \mathrm{C}$ using T4 ligase (Promega) or Quick Ligation kit (New England Biolabs) at a molar ratio of 1:3 (vector:insert). The final constructs and orientation of inserts were confirmed by direct sequencing.

Lentiviral-mediated SNAP-25 RNAi. Double-stranded RNAi sequences targeting distinct regions of mouse SNAP-25 (engineered to mimic endogenous microRNA structure) were subcloned into a pcDNA6.2-GW/EmGFP-miR vector (Invitrogen). Cocistronic expression of EmGFP and targeting microRNA enabled visual identification of cells expressing RNAi. The sense DNA strand coding for SNAP-25 RNAi-1 is TGCTGTACAGGGACACACACAAAGCCGTTTTGGCCACTGACTGACGGCTTTGTGTGTCCCTGTA and that of SNAP-25 RNAi-2 is TGCTGATATGACGGAGGTTTCCGATGGTTTTGGCCACTGACTGACCATCGGAACTCCGTCATAT. For nontargeting (NT, control) RNAi, a sequence that does not target any known vertebrate gene was used (GAAATGTACTGCGCGTGGAGACGTTTTGGCCACTGACTGACGTCTCCACGCAGTACATTT) (bolded regions represent the sequences corresponding to coding nucleotides in the mouse SNAP-25 cDNA). All constructs and orientation of inserts were confirmed by sequencing. To express SNAP-25 RNAi using a lentivirus, the SNAP-25 RNAi-2 sequence was excised by SalI and XhoI and subcloned into a self-inactivating lentiviral transfer vector (pCMV \#207, gift from
Antonia Follenzi, Albert Einstein College of Medicine). 293T cells in 15 $\mathrm{mm}$ plates were cotransfected with the transfer vector and packaging plasmids pMDL, pRev, and pVSV-G using the calcium phosphate method as described previously (Follenzi and Naldini, 2002). Forty-eight hours later, the medium was collected, filtered through a $0.45 \mu \mathrm{m}$ filter, and centrifuged at $70,000 \times g$ for $3 \mathrm{~h}$. The viral pellet was resuspended in $200 \mu \mathrm{l}$ of sterile PBS. All viral preparations were used after dilution to a concentration of 1:100 with medium.

Electrophysiology of NMDARs expressed in Xenopus oocytes. Adult female Xenopus laevis frogs (Nasco) were anesthetized in 0.15\% 3-aminobenzoic acid ethyl ester (Sigma) and their oocytes were isolated with collagenase B $(0.2 \% \mathrm{w} / \mathrm{v})$ and prepared as described(Kushner et al., 1988). Stage V and VI oocytes were microinjected with 4-8 ng of $\mathrm{NR} 1_{100} / \mathrm{NR} 2 \mathrm{~A}$ ( $1: 3$ by weight) cRNA. Two days after injection, they were injected with either WT or mutant SNAP-25 cRNA (20 ng). Two electrode whole-cell voltage-clamp recording was performed $1 \mathrm{~d}$ after the injection of SNAP-25 CRNA in $\mathrm{Mg}^{2+}$-free, $\mathrm{Ca}^{2+}$ or $\mathrm{Ba}^{2+}$ (1 mM) Ringer solution with microelectrodes filled with $3 \mathrm{M} \mathrm{KCl,} 10 \mathrm{~mm}$ HEPES, pH 7.2, using GeneClamp 500 (Molecular Devices, Foster City, CA). Data were digitized with pCLAMP6 (Molecular Devices). Responses were elicited by bath application of $300 \mu \mathrm{M}$ NMDA with $10 \mu \mathrm{M}$ glycine at a holding potential of $-60 \mathrm{mV}$. Endogenous PKC was activated by bath application of the phorbol ester 12-O-tetradecanoylphorbol 13-acetate (TPA, 100 $\mathrm{nm}$; Sigma) for $10 \mathrm{~min}$. PKC potentiation was expressed as the ratio of the steady-state currents after TPA treatment to those obtained before TPA application. All experiments were performed at room temperature (RT). Data are presented as mean \pm SEM.

Western blotting for p-SNAP-25 and SNAP-25 in HEK-293 cells and cortical neurons. For HEK-293 cells, $5 \times 10^{6}$ cells (ATCC) were seeded in $60 \mathrm{~mm}$ dish and transfected with WT or mutant SNAP-25/pIRES2-EGFP constructs $(6 \mu \mathrm{g})$ using Lipofectamine 2000 (Invitrogen). Twenty-four hours after transfection, cells were treated with vehicle (DMSO control) or TPA (100 nM) for $15 \mathrm{~min}$, scraped to one side, and pelleted by centrifugation. For neurons, one cortical hemisphere was trypsinized, triturated, and plated on to a $60 \mathrm{~mm}$ dish in Minimal Essential Medium (MEM, Invitrogen) for $24 \mathrm{~h}$ and switched to Neurobasal medium supplemented with B27 and GlutaMax (Invitrogen). Neurons at 9 days in vitro (DIV) in culture were stimulated with TPA (100 nM) with or without bisindolylmaleimide I (Bis, $1 \mu \mathrm{M}$, Calbiochem), and with or without phosphatase inhibitors okadaic acid (100 nM, Calbiochem) and cyclosporin $\mathrm{A}(\mathrm{CsA}, 2 \mu \mathrm{M})$ at $37^{\circ} \mathrm{C}$ for $15 \mathrm{~min}$. TPA, Bis, and CsA were dissolved in DMSO as $10,000 \times$ stock solutions. Following treatment, neurons were rinsed once with ice-cold PBS and scraped to one side (Nunc) in PBS supplemented with $1 \%$ protease inhibitor (Sigma) and $1 \%$ phosphatase inhibitor cocktail 1 (Sigma). Following centrifugation at $16,000 \times g$ at $4^{\circ} \mathrm{C}$ for $1 \mathrm{~min}$, pelleted cells were lysed in lysis buffer containing the following (in $\mathrm{mm}$ ): 25 Tris- $\mathrm{HCl}, 100 \mathrm{NaCl}, 5$ EDTA, 5 EGTA, $1 \%$ Triton $\mathrm{X}-100,1 \%$ protease inhibitor, and $1 \%$ phosphatase inhibitor I (Sigma), $\mathrm{pH} 7.40$, at $4^{\circ} \mathrm{C}$ for $30 \mathrm{~min}$. Insoluble material was spun down at $16,000 \times g$ for $15 \mathrm{~min}$ and protein content in the supernatant was subjected to BCA protein assay. Total protein $(30 \mu \mathrm{g})$ was loaded on to a $4-12 \%$ Bis-Tris acrylamide gel (Invitrogen) and transferred for $1 \mathrm{~h}$ (Novex system, Invitrogen) on to a PVDF membrane. Membranes were blocked in 5\% nonfat dry milk in TBST $(0.05 \%$ Tween 20) for $30 \mathrm{~min}$ at room temperature (RT), incubated with an anti-pSNAP-25 antibody (1:500; raised against the peptide MEKADS- $\mathrm{PO}_{4}^{3-}$ NKTRI corresponding to residues 182-192 of SNAP-25 including p-Ser187 in the center) (Iwasaki et al., 2000), or anti-SNAP-25 antibody (directed against the $\mathrm{N}$ terminus, 1:3000-5000, BD Transduction Laboratories), and detected with anti-rabbit (1:5000) or anti-mouse horseradish peroxidase (1:5000, GE Healthcare) secondary antibodies and enhanced chemiluminescence. Band intensities were quantified with Scion Image v. 4.0.3.2 (Scion) or Image (NIH).

Immunofluorescence staining of SNAP-25 and p-SNAP-25 in HEK-293 cells and neurons. HEK-293 cells $\left(10^{5}\right)$ were seeded on to $12 \mathrm{~mm}$ coverslips in a 24-well plate and transfected with WT or mutant SNAP-25/ pIRES2-EGFP $1 \mathrm{~d}$ after. Cells were incubated with a transfection mixture containing $0.4 \mu \mathrm{g}$ of DNA with $1.2 \mu \mathrm{l}$ of FuGENE (Roche Applied Science) in OptiMEM (Invitrogen). HEK cells at $24-30 \mathrm{~h}$ posttransfection 
were stimulated with TPA $(100 \mathrm{nM})$ with or without Bis $(1 \mu \mathrm{M})$ for 15 min. Cells were fixed in 4\% paraformaldehyde for 5-10 min at RT, blocked, and permeabilized in $10 \%$ normal goat serum, $0.2 \%$ bovine serum albumin, and $0.1 \%$ Triton X-100 in PBS (contained 10 mm phosphate, $138 \mathrm{~mm} \mathrm{NaCl}$ and $2.7 \mathrm{~mm} \mathrm{KCl}$, pH 7.4). The p-Ser187-SNAP-25 antibody was a gift from M. Takahashi (Kitasato University, Kitasato, Japan). Rabbit (p-SNAP-25, 1:250) and mouse (SNAP-25, 1:500, BD Biosciences PharMingen) primary antibodies were incubated together at $4^{\circ} \mathrm{C}$ overnight, and were labeled with secondary antibodies conjugated to either AMCA, Alexa Fluor 488, Cy2 or Cy3 fluorophores (Jackson Immunoresearch or Invitrogen). Coverslips were mounted with an antifade reagent, ProLong (Invitrogen). Stained cells were visualized and photographed with an Olympus AX70 microscope using a 60× PlanApo oilimmersion lens (NA 1.40) and digitized using MagnaFire software (v. 2.1). Quantification of p-SNAP-25 intensity levels was performed by selecting for the entire HEK cell, rather than the leading edge, because it was not technically possible to arbitrarily draw the boundaries under basal conditions (low p-SNAP-25 levels). Thus, values as reported for HEK-293 cells may represent an underestimate of the true levels of p-SNAP-25 at the leading edge. Quantification of p-SNAP-25 intensity levels in neurons was performed by selecting the dendrites.

Electrophysiology of NMDA-elicited currents in hippocampal neurons. Dissociated cultures of hippocampal neurons were prepared from embryonic day 18 rats according to the methods of Banker and Goslin (1988). Hippocampal neurons (DIV 7-14) were transfected with $4 \mu \mathrm{g}$ of WT or SNAP-25(S187A) in pIRES2-EGFP vector using a modified calcium phosphate method (Jiang et al., 2004) for 1-2 h that involved dissolution of the calcium phosphate precipitate in slightly acidic medium (Neurobasal) that had been equilibrated with $8 \% \mathrm{CO}_{2}$. Twenty-four hours later, NMDA-elicited whole-cell currents were recorded by $5 \mathrm{~s}$ bath application of $100 \mu \mathrm{M}$ NMDA and $10 \mu \mathrm{M}$ glycine. Near steady-state currents were measured at the end of the brief perfusion of agonists $(5 \mathrm{~s})$. The external solution contained the following (in mM): $145 \mathrm{NaCl}, 2.5 \mathrm{KCl}, 10$ HEPES, 10 glucose, $2 \mathrm{CaCl}_{2}, \mathrm{pH} 7.4$ and $\sim 10 \mathrm{~mm}$ sucrose to adjust osmolality to $310-320 \mathrm{mOsm}$. Recording pipettes were pulled from borosilicate glass (A-M System) and open-tip resistance after heat polishing (Narishige) was typically $2-5 \mathrm{M} \Omega$ with an internal solution of (in $\mathrm{mm}$ ): $120 \mathrm{CsCH}_{3} \mathrm{SO}_{3}, 10 \mathrm{CsCl}, 10$ HEPES, 10 EGTA, 4 MgATP, $0.4 \mathrm{NaGTP}, 0.1$ $\mathrm{CaCl}_{2}, 0.5 \mathrm{MgCl}_{2}, 5$ phosphocreatine, adjusted to $\mathrm{pH} 7.3$ with $\mathrm{CsOH}$ and 290-300 mOsm. The constitutively active form of PKC (PKM, 2 nM; Sigma) was dialyzed into the cell by its inclusion in the pipette, and NMDA currents were continually monitored and recorded using an AxoPatch-1D amplifier (Molecular Devices) and digitized by the 1322A Digidata D/A converter (Axon) and pCLAMP 9.2 software. Signals were low-pass filtered at $2 \mathrm{kHz}$ and digitized at $5 \mathrm{kHz}$. $V_{\mathrm{h}}=-60 \mathrm{mV}$. Potentiation of NMDA currents was measured at 5 min after break-in and delivery of PKM and was expressed as a ratio to the amplitude of the basal current recorded at $0 \mathrm{~min}$. SNAP-25 C-terminal peptides (70\% purity) were custom-synthesized by Anaspec, and used at $10 \mu \mathrm{M}$ in the pipette. Peptides were dissolved in water (as $1000 \times$ stocks), aliquoted and thawed for use on the day of experiment. The sequence for the blocking peptide was MEKADANKTRI and scrambled peptide was KANAKTDEIRM. For peptide recordings, after the washout of NMDA and glycine, S-AMPA ( $25 \mu \mathrm{M}$; Sigma) was bath-applied for $1 \mathrm{~s}$ to simultaneously monitor AMPAR- and NMDAR-mediated currents in the same cell. Chelerythrine $(1 \mu \mathrm{M})$, an inhibitor of the catalytic domain of PKC, was applied at the end of experiments to confirm PKM activity. Clostridium botulinum neurotoxins (BoNT; from List Biological Laboratories) were reconstituted according to manufacturer's instructions and applied to cells for $1 \mathrm{~h}$ at $37^{\circ} \mathrm{C}$ at $1 \mu \mathrm{g} / \mathrm{ml}(6.7 \mathrm{nM})$ final concentration.

Electrophysiology of isolated NMDA EPSCs in hippocampus. Transverse hippocampal slices were prepared from P16-P21 C57BL/6 mice, as described previously (Christensen et al., 2004). Electrophysiological recordings were performed from neurons visually identified by infrared differential interference contrast microscopy using a $40 \times$ waterimmersion objective. All experiments were performed at room temperature $\left(22-25^{\circ} \mathrm{C}\right)$. Slices were continuously perfused with (in $\mathrm{mm}$ ): 124 $\mathrm{NaCl}, 3 \mathrm{KCl}, 1.25 \mathrm{KH}_{2} \mathrm{PO}_{4}, 1 \mathrm{MgCl}_{2}, 2 \mathrm{CaCl}_{2}, 26 \mathrm{NaHCO}_{3}$, and 10 glucose, pH 7.3 (300 mOsm), supplemented with picrotoxin (50 $\mu \mathrm{M})$, CNQX $(10 \mu \mathrm{M})$ and LY303070 (the active isomer of GYKI-53655; $25 \mu \mathrm{M}$ ) to isolate synaptic responses mediated by NMDARs. Drugs were applied by switching between gravity-fed perfusion lines. EPSCs were evoked by paired-pulse stimulation (interstimulus interval of $100 \mathrm{~ms}$ ) of mossy fibers by placing a bipolar electrode in the dentate granule cell layer. Tight-seal ( $>1$ G $\Omega$ ) whole-cell recordings were obtained from CA3 pyramidal neurons using patch pipettes pulled from borosilicate glass that had a resistance of 3-5 M $\Omega$ when filled with the following internal solution (in mM): $130 \mathrm{CsMeSO}_{3}, 4 \mathrm{NaCl}, 10 \mathrm{HEPES}, 0.2$ EGTA, and $10 \mathrm{TEA}$, 5 QX-314, 4 ATP and 0.5 GTP (pH 7.3, 287 mOsm). PKC activators, PDBu $(1 \mu \mathrm{M})$ or PKM $(1 \mu \mathrm{M})$, and anti-SNAP25 antibody $(20 \mathrm{mg} / \mathrm{ml}$; SMI 81, Sternberger Monoclonals), denatured (boiled) anti-SNAP25 antibody, SNAP-25 scrambled or blocking peptide $(50 \mu \mathrm{M})$ alone or in combination were used in the patch pipette. Series resistance $(<20 \mathrm{M} \Omega)$ was regularly monitored during recordings, and cells were rejected if resistance changed $>15 \%$ during the experiment. Data were filtered at 2 $\mathrm{kHz}$, digitized, acquired through Axopatch 200A amplifier (Molecular Devices) and pClamp 8.0 software. Statistical significance was evaluated by the two-tailed unpaired Student's $t$ test.

Western blot analysis of NMDAR surface expression. Cortical neurons in culture (DIV 9-11) were treated with TPA with or without phosphatase inhibitors, washed, and treated with membrane-impermeable EZLink Sulfo-NHS-SS-Biotin (Sulfosuccinimidyl 2-(biotinamido)-ethyl-1, 3 -dithiopropionate, $1 \mathrm{mg} / \mathrm{ml}$; Pierce) for $30 \mathrm{~min}$ at $4^{\circ} \mathrm{C}$. Proteins were extracted in lysis buffer containing Tris- $\mathrm{HCl}(\mathrm{pH} 7.40,25 \mathrm{~mm}), \mathrm{NaCl}$ (150 mm), EDTA (pH 8.0, 1 mm), SDS (0.1\%), Na deoxycholate $(0.5 \%)$, and protease and phosphatase inhibitors for $30 \mathrm{~min}$ at $4^{\circ} \mathrm{C}$, and surface proteins were pulled down with NeutrAvidin beads (Pierce) $\mathrm{O} / \mathrm{N}$ at $4^{\circ} \mathrm{C}$ and released from the beads by boiling with DTT $(1 \mathrm{~mm})$. Total and surface proteins were subjected to SDS-PAGE and Western blotting using a monoclonal antibody 54.1 directed against the extracellular loop of the NR1 subunit (1:5000; gift from J.H. Morrison, Mount Sinai) or GluR1 (1:1000, Millipore AB1504).

\section{Results}

Ser187, but not Ser28 and Thr29, of SNAP-25 is an important PKC target

To examine a possible role for SNAP-25 as a PKC target critical to NMDAR insertion, we expressed NR1-4b/NR2A receptors together with WT and mutant SNAP-25 in Xenopus oocytes and recorded NMDA-elicited whole-cell currents before and after PKC activation. Xenopus oocytes are geometrically simple cells and provide a homogeneous source of NMDARs. NR1-4b/NR2A receptors exhibit the highest surface expression (Okabe et al., 1999) and highest PKC potentiation in oocytes (Durand et al., 1993). Application of the PKC-activating phorbol ester TPA (100 $\mathrm{nM}, 10 \mathrm{~min}$ ) potentiated NMDA currents by $\sim 8$-fold in cells expressing NMDARs in the absence of exogenous SNAP-25 (control; Fig. 1a). PKC potentiation, defined as the ratio of steadystate NMDA current after PKC activation to that before PKC activation, was $8.30 \pm 0.67(n=26, p<0.001$ vs control; in $1 \mathrm{~mm}$ $\left.\mathrm{Ca}^{2+}\right)$. The specific PKC inhibitor Ro-31-8220 (5 $\mu \mathrm{M}, 15 \mathrm{~min}$ preincubation) completely abolished TPA-induced potentiation of NMDA-elicited currents (from $4.30 \pm 0.56$ to $1.01 \pm 0.29$ fold, $n=3, p<0.01 ; 1 \mathrm{mM} \mathrm{Ba}^{2+}$ ), indicating that TPA potentiation is PKC-mediated. Expression of wild-type (WT) SNAP-25 did not significantly alter basal or potentiated NMDA currents (Fig. 1b). Expression of dominant-negative SNAP-25 (lacking the last 20 amino acids in the $C$ terminus, SNAP- $25 \Delta 20$ or dnSNAP25) (Yao et al., 1999; Lan et al., 2001a) markedly reduced basal NMDA currents (defined as the steady-state phase of the current before PKC potentiation and normalized to WT SNAP-25 current amplitudes; $25.7 \pm 6.9 \%$ of WT, $n=20, p<0.001$; Fig. $1 c$ ) and PKC potentiation (normalized to WT SNAP-25 potentia- 
a

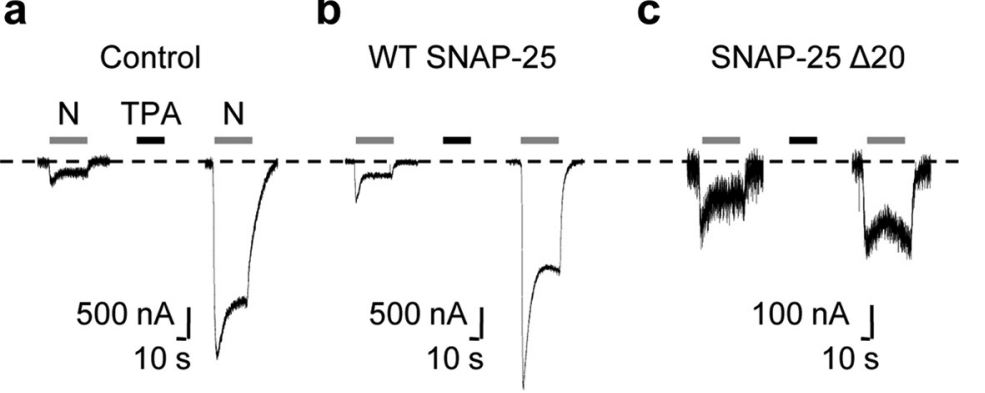

d

e $\quad$ f

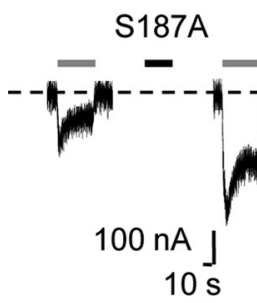

g

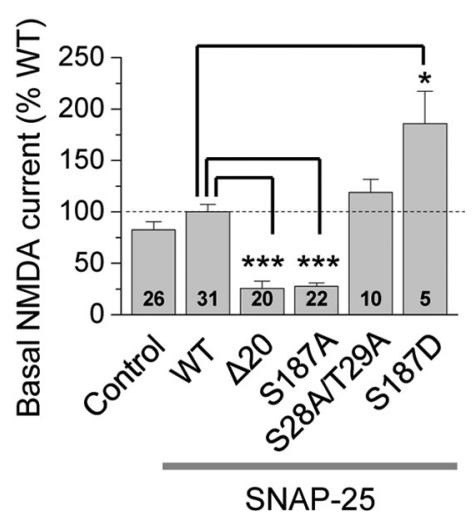

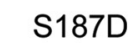

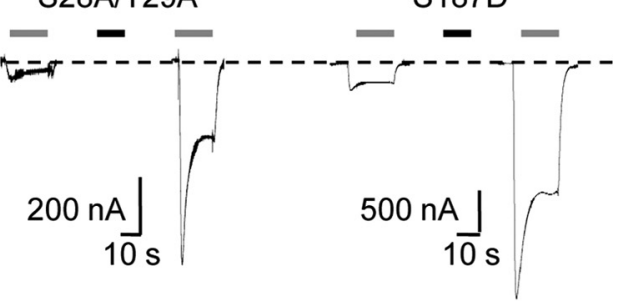

h

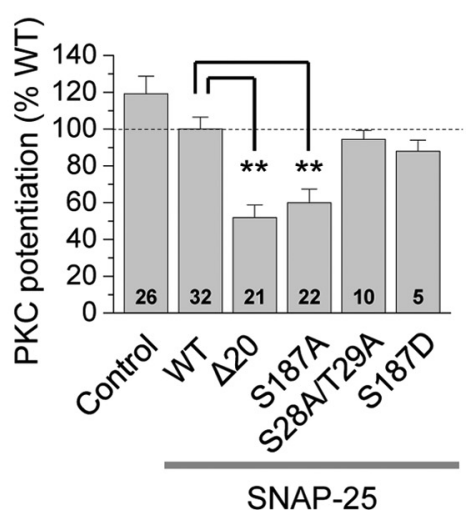

Figure 1. Ser187, but not Ser28 and Thr29, of SNAP-25 is critical to PKC potentiation of NMDA currents. $\boldsymbol{a}-\boldsymbol{f}$, Representative experiments showing PKC potentiation of NMDA-elicited currents recorded from Xenopus laevis oocytes expressing NR1-4b/NR2A and WT or mutant SNAP-25, $24 \mathrm{~h}$ after injection of SNAP-25 CRNA. NMDA currents were elicited by bath application of NMDA (N, 300 $\mu \mathrm{m}$ with $10 \mu \mathrm{m}$ glycine; gray bars above current traces) and recorded by two-electrode voltage clamp at $V_{\mathrm{h}}=-60 \mathrm{mV}$ in $1 \mathrm{mM}$ $\mathrm{Ca}^{2+}$ and $0 \mathrm{Mg}^{2+} . \boldsymbol{a}$, Application of the PKC-activating phorbol ester 12-0-tetradecanoylphorbol 13-acetate (TPA, $100 \mathrm{~nm}, 10$ min, black bar) potentiated NMDA currents by $\sim 8$-fold in control $\left(\mathrm{H}_{2} 0\right.$-injected) oocytes. PKC potentiation is defined as the ratio of steady-state NMDA current after to that before PKC activation. $\boldsymbol{b}$, Expression of WT SNAP-25 does not detectably alter PKC potentiation of NMDA-elicited currents. $c$, The dominant-negative mutant of SNAP-25, SNAP25 $\Delta 20$, markedly reduced the basal NMDA current and PKC potentiation. Note the change in scale. $\boldsymbol{d}$, A point mutation in which Ser187 was replaced by Ala (S187A) in SNAP-25 reduced both basal NMDA currents and PKC potentiation to an extent indistinguishable from SNAP-25 $\Delta 20$. $\boldsymbol{e}$, Replacement of Ser28 and Thr29 by Ala (SNAP-25 S28A/T29A) did not detectably alter basal NMDA currents or PKC potentiation. $\boldsymbol{f}$, The phosphomimetic mutant, SNAP-25 S187D, markedly enhanced basal NMDA currents without affecting PKC potentiation. $\boldsymbol{g}, \boldsymbol{h}$, Summary bar graphs showing effects of WT and mutant SNAP-25 on basal NMDA currents $(\boldsymbol{g})$ and PKC potentiation $(\boldsymbol{h})$. PKC potentiation in uninjected oocytes and oocytes expressing mutant SNAP-25 constructs was normalized to that in cells expressing WT SNAP-25. Numbers on bars indicate the number of oocytes $(n)$ involving 3-5 independent experiments performed from different batches of oocytes. Data represent means \pm SEM. ${ }^{*} p<0.05 ;{ }^{* *} p<0.01 ;{ }^{* * *} p<0.001$.

PKC phosphorylation, a role for PKCdependent phosphorylation of SNAP-25 in NMDAR potentiation is unclear. To examine the possibility that SNAP-25 is a functionally relevant target of PKC phosphorylation and to identify residue(s) in SNAP-25 that are critical to PKC potentiation of NMDARs, we expressed NMDARs together with WT or mutant SNAP-25 lacking one or more of its putative phosphorylation sites (Ser187, Ser28, Thr29) in Xenopus oocytes. Replacement of the serine residue 187 in SNAP-25 with an alanine (Ser187Ala or S187A) markedly reduced basal NMDA currents $(27.5 \pm 3.4 \%$ of WT, $n=22, p<0.001$; Fig. $1 d$ ) and degree of PKC potentiation (59.9 $\pm 7.5 \%$ of WT, $n=22, p<0.01$; Fig. $1 d)$, reductions similar to those observed for dnSNAP-25 $\Delta 20$. Thus, in oocytes, a single point mutation in SNAP-25 is sufficient to suppress constitutive and regulated NMDAR exocytosis. In contrast, elimination of the other two putative sites of PKC phosphorylation, Ser28 and Thr29, even in combination did not detectably alter either basal or potentiated currents (basal currents, $119 \pm 13 \%$ of $\mathrm{WT}, n=10, p>0.05$; PKC potentiation, $94.5 \pm 4.8 \%$ of WT, $n=10, p>0.05$; Fig. 1e). These findings indicate that Ser 187 is the exclusive site of PKC phosphorylation in SNAP-25 that is functionally relevant to NMDAR insertion. The phosphomimetic mutant SNAP-25(S187D), which mimics phosphorylation by replacement of Ser with the negatively charged residue aspartate (D), markedly enhanced basal NMDA currents even in the absence of PKC activation ( $186 \pm 31 \%$ of WT, $n=5$, $p<0.05$; Fig. $1 f$ ), but did not detectably alter PKC potentiation $(88.0 \pm 6.1 \%$ of WT, $n=5, p>0.05$; Fig. $1 f-i)$. The fact that mutation of Ser187 into Asp, a nonphosphorylatable residue, does not affect PKC potentiation suggests that Ser 187 of SNAP-25 may not be the only target of PKC phosphorylation involved in NMDAR trafficking. These results suggest that Ser187 of SNAP-25 is a target of PKC phosphorylation relevant to NMDAR potentiation in oocytes. tion; $51.8 \pm 6.9 \%$ of WT, $n=20, p<0.01$; Fig. $1 c$ ). These findings demonstrate a role for SNAP-25 in PKC potentiation of NMDARs. The incomplete $(\sim 50 \%)$ block of basal currents or potentiation could reflect the inability of dnSNAP-25 to completely suppress endogenous SNAP-25 function, the existence of additional pathways for receptor exocytosis and/or a contribution of enhanced channel opening to PKC potentiation.

PKC potentiates NMDA-elicited currents in hippocampal neurons primarily via rapid insertion of NMDARs at the cell surface (Lan et al., 2001a). Although SNAP-25 is a known target of
PKC phosphorylates SNAP-25 at Ser187

To directly show that PKC phosphorylates SNAP-25 at Ser187, we performed two experiments. First, we expressed WT and mutant SNAP-25(S187A) under the pIRES2-EGFP vector, which allows transfected cells to be identified by means of its green fluorescence, in HEK-293 cells and assessed PKC-induced phosphorylation by Western blot analysis. Application of PKCactivating phorbol ester TPA (100 nM, $15 \mathrm{~min}$ ) to HEK-293 cells induced phosphorylation of SNAP-25 at Ser187, as assessed by Western blots probed with a phospho-specific antibody (Fig. 2a, 
top). Coapplication of the potent and specific PKC inhibitor bis-indoylmaleimide I (Bis, $1 \mu \mathrm{M}$ ) completely abolished TPAinduced phosphorylation of SNAP-25, confirming that TPA acts via PKC to exert its effects (Fig. 2a). In contrast, cells expressing mutant SNAP-25(S187A) exhibited robust SNAP-25 expression, but little or no p-SNAP-25 either before or after application of TPA (Fig. 2a). Stripping and reprobing the membrane with an antibody directed against full-length SNAP-25 revealed equal loading of samples and absence of SNAP-25 in untransfected cells, indicating the specificity of the antibody.

Second, we expressed WT and mutant SNAP-25(S187A) in HEK-293 cells and performed immunolabeling of total and p-SNAP-25. Under basal conditions, SNAP-25 localized to the plasma membrane, as well as to the Golgi apparatus (perinuclear labeling); little or no p-SNAP-25 was detected (Fig. 2b). Application of TPA did not detectably alter the abundance or cellular localization of total SNAP-25, but produced a dramatic increase in p-SNAP-25 immunofluorescence, prominent at the edges of the cells (Fig. 2c). The specific PKC inhibitor Bis again abolished TPA-induced phosphorylation of SNAP-25, indicating that SNAP-25 phosphorylation is PKC-mediated (Fig. 2d). In contrast, cells expressing mutant SNAP-25(S187A) exhibited robust SNAP-25 immunofluorescence, but little or no p-SNAP-25 immunofluorescence either before or after application of TPA (Fig. 2e-g). These findings demonstrate that PKC promotes phosphorylation of SNAP-25 at Ser187 in HEK-293 cells. Although we cannot rule out additional sites of phosphorylation at Ser28 and Thr29, data in Figure 1 indicate that were phosphorylation of these sites to occur, it would not be functionally relevant to PKC potentiation.

The results thus far demonstrate that SNAP-25 is a functionally relevant target of $\mathrm{PKC}$ involved in $\mathrm{PKC}$ potentiation of NMDARs in oocytes and that PKC phosphorylates SNAP-25 at Ser187 in HEK-293 cells. To examine whether Ser187 of SNAP-25 is a target of PKC phosphorylation in neurons, we performed two experiments. First, we treated cortical neurons (DIV 19) with TPA or vehicle and subjected cell lysates to Western blot analysis. Cortical neurons exhibited little or no p-SNAP-25 basally, whereas upon TPA stimulation, p-SNAP-25 was markedly induced (Fig. 3a). These findings are in confirmation of observations in PC12 cells (Iwasaki et al., 2000), chromaffin cells (Nagy et al., 2002) and HEK-293 cells (Fig. 2). Application of okadaic acid $(\mathrm{OA}, 100 \mathrm{nM})$ with cyclosporine A (CsA, $2 \mu \mathrm{M})$, a mixture that inhibits protein phosphatases 1 (PP1), PP2A, and PP2B (also known as calcineurin), enhanced TPA-elicited phosphorylation of SNAP-25 at Ser187 (Fig. 3a, top); the mixture alone did not induce phosphorylation of SNAP-25 at Ser187 (data not shown). Application of the specific PKC inhibitor Bis completely abolished TPA-induced phosphorylation of SNAP-25 at Ser 187 in the absence or presence of phosphatase inhibitors (Fig. $3 a$, top). Summary data indicate that the phosphatase inhibitors enhanced
SNAP-25

\section{WT S187A SNAP-25 S187A}

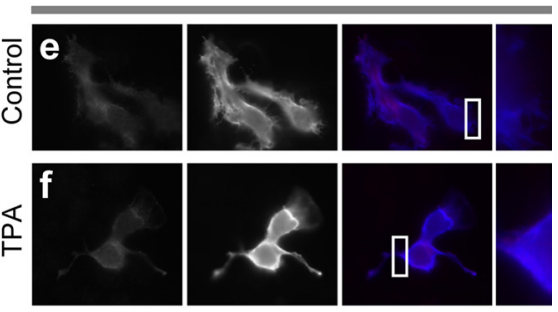

g

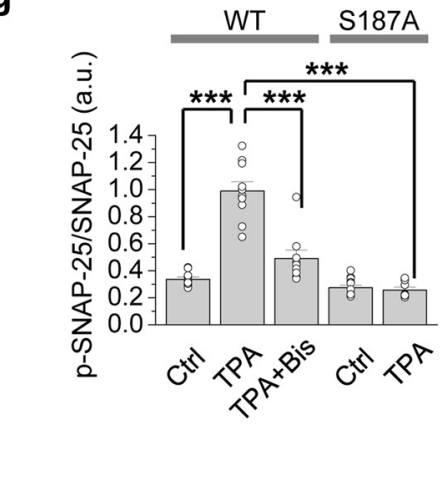

Figure 2. PKC phosphorylates SNAP-25 in heterologous cells. $\boldsymbol{a}$, HEK-293 cells overexpressing WT and S187A SNAP-25 were treated with TPA (100 nM, $15 \mathrm{~min}$ ) in the absence or presence of Bis. Cell lysates were subjected to Western blotting and probed

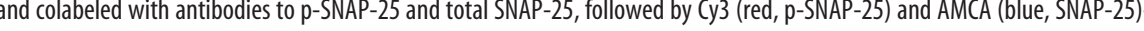
phosphorylation of SNAP-25.e, $\boldsymbol{f}$, TPA does not promote phosphorylation of mutant SNAP-25(S187A). $\boldsymbol{g}$, Summary bar graph of 2 for each condition; ${ }^{* * *} p<0.001$

TPA-induced phosphorylation of SNAP-25 by $\sim 2$-fold and that Bis completely abolished phosphorylation (TPA vs control, $\mathrm{TPA}+\mathrm{Bis}$ vs TPA and TPA $+\mathrm{CsA}+\mathrm{OA}+\mathrm{Bis}$ vs TPA, $n=4$, $p<0.001$; TPA + CsA + OA vs TPA, $n=4, p<0.05$; Fig. $3 b)$. In contrast, neither PKA inhibitors $\left(\mathrm{PKI}_{(14-22)}\right.$ and $\left.\mathrm{H}-89\right)$ nor a CaMKII inhibitor (KN-93) attenuated SNAP-25 phosphorylation in neurons (supplemental Fig. 1, available at www.jneurosci. org as supplemental material). These findings strongly suggest that the TPA-induced phosphorylation of SNAP-25 is PKCdependent in HEK-293 cells and neurons.

Second, we performed immunolabeling of hippocampal neurons (DIV 14) with antibodies to SNAP-25 and p-SNAP-25. Under basal conditions, SNAP-25 immunolabeling was prominent in cell bodies and processes of neurons (Fig. $3 c, d$ ). In contrast, p-SNAP-25 immunolabeling was relatively low, presumably due to low basal PKC activity and/or high phosphatase activity. Application of TPA did not detectably alter the abundance or cellular localization of total SNAP-25, but markedly increased pSNAP-25 immunofluorescence (Fig. 3c,d). Quantification of fluorescence intensity showed that TPA increased the p-SNAP25/total SNAP-25 ratio in dendrites by $\sim 50 \%$ (control vs TPA; p-SNAP-25: $100 \pm 11 \%$ vs $150 \pm 9 \%, p<0.01$; total SNAP-25: $100 \pm 17 \%$ vs $81 \pm 15 \%, p>0.4 ;$ p-SNAP-25/total SNAP-25: $100 \pm 10 \%$, vs $229 \pm 40 \%, n=7, p<0.05$; Fig. $3 d)$. These findings indicate that PKC phosphorylates SNAP-25 at Ser-187 in neurons and that after PKC stimulation, p-SNAP-25 is enhanced in neuronal processes. The results do not exclude the possibility that PKC also phosphorylates other targets such as the 


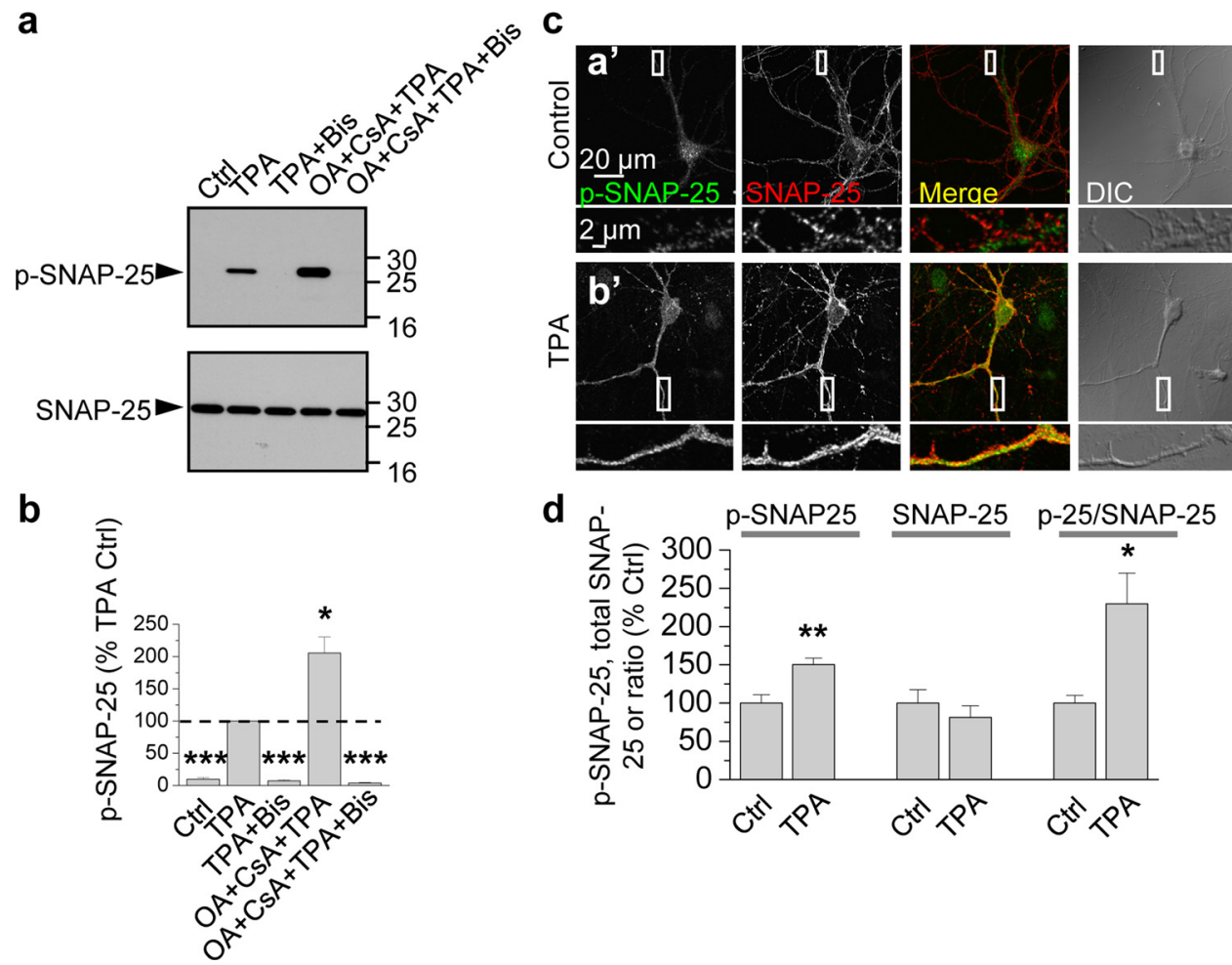

Figure 3. PKC phosphorylates SNAP-25 in neurons. $\boldsymbol{a}$, Dissociated cortical neurons in culture (DIV 9) were treated with TPA (100 nM, $15 \mathrm{~min}$ ) in the absence or presence of Bis and the phosphatase inhibitors okadaic acid (OA, $100 \mathrm{~nm})$ and cyclosporine A (CSA, $2 \mu \mathrm{M})$, lysed, and protein samples were subjected to Western blots probed with the p-SNAP-25 antibody. TPA induced robust phosphorylation of SNAP-25 at Ser187 (p-SNAP-25, upper blot, second lane), which was enhanced by phosphatase inhibitors (fourth lane) and blocked by the PKC inhibitor Bis (third lane) even in the presence of phosphatase inhibitors (fifth lane). Stripping and reprobing with an antibody to total SNAP-25 revealed equal loading of proteins in all lanes (bottom). $\boldsymbol{b}$, Summary bar graph showing p-SNAP-25/SNAP-25 normalized to the TPA sample; $n=4$ independent experiments; ${ }^{*} p<0.05,{ }^{* * *} p<0.001 . \boldsymbol{c}, \boldsymbol{d}$, Hippocampal neurons in the absence (control; $0.01 \%$ DMSO) or presence of TPA treatment were fixed, permeabilized and colabeled with antibodies for p-SNAP-25 and SNAP-25 and decorated with Alexa Fluor 488- and Cy3-conjugated secondary antibodies, respectively. Representative confocal images showing that neuronal somata and dendrites exhibited low p-SNAP-25 labeling under basal conditions ( $\boldsymbol{a}^{\prime}$ ); upon TPA stimulation, p-SNAP-25 immunolabeling markedly increased $\left(\boldsymbol{b}^{\prime}\right)$. Bottom, high-magnification images of regions indicated in boxes above. $\boldsymbol{d}$, Dendritic regions were selected based on the differential interference contrast (DIC) images, and values of integrated intensity divided by area were plotted. Summary bar graph showing that intensity levels of p-SNAP-25 (left), but not total SNAP-25 (center), increased. Thus, the ratio of p-SNAP-25/SNAP-25 increased (right). ${ }^{*} p<0.05 ;{ }^{* *} p<0.01$.

presynaptic proteins munc-18 (Wierda et al., 2007) and dynamin (Robinson et al., 1993) and/or that it indirectly phosphorylates SNAP-25 via activation of another kinase. It should be noted that at this resolution, it is not possible to distinguish labeling in preversus postsynaptic structures and may be difficult to distinguish en passant axons versus dendrites.

\section{PKC-mediated insertion of NMDARs in neurons is SNARE-dependent}

The results reported thus far demonstrate that PKC phosphorylates SNAP-25 at Ser187 in neurons, but do not implicate SNAP-25 as a functionally relevant substrate of PKC phosphorylation in neurons. Toward this end, we undertook three experimental approaches. First, we monitored PKC potentiation of NMDA-elicited currents by whole-cell patch-clamp recording from cultured hippocampal neurons (DIV 10-14) pretreated with inactivated or active botulinum neurotoxin (BoNT) A, an isoform that cleaves SNAP-25 (but not SNAP-23) and prevents SNARE-dependent exocytosis (Yao et al., 1999). We reasoned that if PKC potentiated NMDARs via SNARE-dependent exocytosis, then cleavage of SNAP-25 and/or its binding partners would prevent PKC potentiation. NMDA currents were elicited once per minute by bath-application of NMDA (N, $100 \mu \mathrm{M}$ with $10 \mu \mathrm{M}$ glycine, $5 \mathrm{~s}$ application). Introduction of the constitutively active form of PKC, PKM (2 nM), via the recording pipette to neurons rapidly (within $5 \mathrm{~min}$ after break-in) potentiated
NMDA currents in cells treated with inactive BoNT A (inactivated by boiling for $5 \mathrm{~min}$; left) by $\sim 60 \%$ relative to basal currents (potentiation of the peak to $157 \pm 16 \%, p<0.01$; potentiation of steady state to $140 \pm 14 \%, p<0.02$ vs basal currents; Fig. $4 a-c$ ), presumably due in large part to enhanced delivery of NMDARs to the cell surface (Lan et al., 2001a). Treatment of neurons with BoNT A (200 ng/ml; pretreatment for $1 \mathrm{~h})$ did not detectably alter basal NMDA currents (data not illustrated), but abolished PKC potentiation of NMDA currents of both peak and steady-state (SS) phases of NMDA currents in hippocampal neurons (inactive vs active BoNT A: peak, $157 \pm$ $16 \%$ vs $99 \pm 2 \%, n=9 ; p<0.001$; steady state, $140 \pm 14 \%$ vs $106 \pm 5 \%, n=9 ; p<0.02$; Fig. $4 a-c)$. Consistent with SNAREdependent receptor exocytosis, pretreatment with BoNT B (200 $\mathrm{ng} / \mathrm{ml}$ ), which cleaves v-SNARE VAMP2/synaptobrevin-2, also blocked PKM potentiation of NMDA currents (inactive vs active BoNT B: peak, $131 \pm 5 \%$ vs $97 \pm 14 \%, n=4$; $p<0.05$; supplemental Fig. 2, available at www.jneurosci.org as supplemental material). These findings indicate that $\mathrm{PKC}$ potentiation of NMDA responses in hippocampal neurons occurs via SNAP-25mediated, SNARE-dependent exocytosis.

\section{RNAi-mediated depletion of SNAP-25 blocks PKC} potentiation of NMDARs

Second, we examined with the impact of RNAi-mediated knockdown of SNAP-25 on PKC potentiation of NMDA currents. We 
designed two RNAi sequences directed against mouse SNAP-25 cDNA and evaluated them separately for their ability to knockdown SNAP-25 expression in HEK293 cells. A generic RNAi that does not target any known vertebrate gene (nontargeting (NT)-RNAi), served as a negative control (pcDNA6.2). Both SNAP-25 RNAi-1 (directed to bps 470-490 of mouse SNAP-25) and SNAP-25 RNAi-2 (directed to bps 681-701 of SNAP-25), but not NT RNAi, markedly attenuated recombinant SNAP-25 protein expression in HEK-293 cells ( $48 \mathrm{~h}$ after transfection: RNAi-1: to $17 \%$ of control; RNAi-2: to $30 \%$ of control; $72 \mathrm{~h}$ after transfection: both to $4 \%$ of control; supplemental Fig. 3 , available at www.jneurosci.org as supplemental material). To validate the specificity and effectiveness of the SNAP-25 RNAi-2 sequence in cells with neuronal traits, we examined its impact on endogenous SNAP-25 and SNAP-23 abundance in Neuro2A (N2A) cells. N2A cells were transfected with a lentiviral transfer vector driving cocistronic expression of EGFP and SNAP-25 RNAi-2 (hereafter referred to as "SNAP-25 RNAi”). Seventy-two hours after transfection, cells were lysed and subjected to Western blotting for SNAP-25. SNAP-25 RNAi was highly effective in that it markedly reduced SNAP-25 protein abundance relative to that of untransfected cells (not illustrated) or cells transfected with NT (control) RNAi (to 18\%), and was specific in that it did not detectably alter SNAP-23 abundance (Fig. 4d).

To examine the effects of SNAP-25 RNAi on NMDA currents in a physiological milieu, we next infected neurons with lentivirus containing SNAP-25 RNAi or NT RNAi (control) and monitored PKMinduced potentiation of NMDA currents. At $48-72 \mathrm{~h}$ after transduction, SNAP-25 RNAi was robustly expressed, as evidenced by intense EGFP fluorescence (data not illustrated). SNAP-25 RNAi induced little effect on basal NMDA currents, but markedly reduced $\mathrm{PKC}$ potentiation of both peak and steady-state phases of NMDA-elicited currents in hippocampal neurons (NT RNAi: peak, $149 \pm 8 \%$; steady state, $125 \pm 6 \%, n=$ $4, p<0.01$ vs control currents; SNAP-25 RNAi: peak, $102 \pm 4 \%$, steady state, $86 \pm 7 \% ; n=4$, n.s. vs control currents; $p<0.01$ vs NT RNAi; Fig. $4 e-g$ ). Thus, SNAP-25 silencing abolishes PKC potentiation of NMDA responses in hippocampal neurons. These findings strongly suggest that SNAP-25 is required for PKC insertion of NMDARs in neurons.

\section{Phosphorylation of SNAP-25 at Ser187 is critical to PKC insertion of NMDARs in neurons}

Third, we expressed WT or mutant SNAP- 25(S187A) via the pIRES2-EGFP vector in cultured hippocampal neurons and
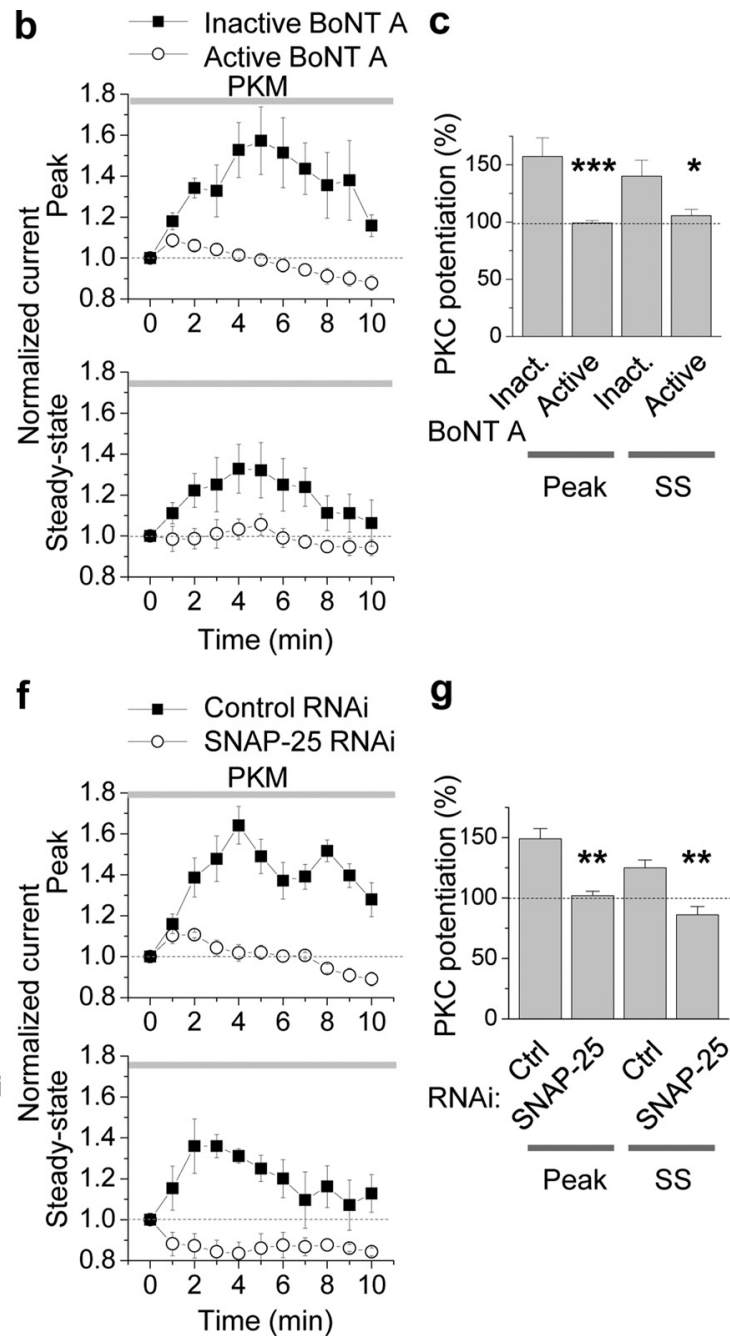

Figure 4. PKC-mediated insertion of NMDARs in neurons requires SNAP-25. $\boldsymbol{a}-\boldsymbol{c}$, Specific cleavage of SNAP-25 by botulinum toxin A (BoNT A) blocked PKM potentiation of NMDA currents. $\boldsymbol{a}$, Whole-cell patch-clamp recordings were performed on hippocampal neurons (DIV $10-14)$ pretreated with inactivated (Inact.; heated at $95^{\circ} \mathrm{C}$ for $15 \mathrm{~min}$ ) or active BoNT A ( $\left.200 \mathrm{ng} / \mathrm{ml}\right)$ for $1 \mathrm{~h}$ at $37^{\circ} \mathrm{C}$. NMDA-elicited currents were monitored every minute by bath-application of NMDA (N, $100 \mu \mathrm{m}$ with $10 \mu \mathrm{m}$ glycine, $5 \mathrm{~s}$ ). Constitutively active PKC, PKM ( $2 \mathrm{~nm}$ ), introduced via the patch pipette, rapidly (within 5 min after break-in) potentiated NMDA currents in cells treated with inactive BoNT A (left). Treatment of neurons with BoNT A abolished PKM potentiation of NMDA currents (right). $\boldsymbol{b}, \boldsymbol{c}$, Summary time course $(\boldsymbol{b})$ and bar graph (c) showing that active $(\bigcirc)$, but not inactive $(\boldsymbol{\square})$, BoNT A abolished PKM potentiation of both peak and steady-state (SS) phases of NMDA currents in hippocampal neurons $(n=9)$. ${ }^{*} p<0.05$; ${ }^{* *} p<0.01$. $\boldsymbol{d}-\boldsymbol{g}$, RNAi-mediated knockdown of SNAP-25 blocked PKM potentiation. $\boldsymbol{d}$, Validation of RNAi-mediated knockdown of endogenous SNAP-25 in N2A cells. N2A cells were transfected with a lentiviral transfer vector driving expression of EGFP and SNAP-25 RNAi cocistronically. Seventy-two hours after transfection, cells were lysed and subjected to Western blotting for SNAP25. A sequence directed against SNAP-25, but not an unrelated sequence (control), markedly reduced SNAP-25 expression. Stripping and reprobing for $\beta$-actin revealed equal loading and that SNAP-23 expression is unaffected. *Nonspecific band. $\boldsymbol{e}$, Knockdown of SNAP-25 blocks PKM potentiation. Whole-cell recordings were performed on neurons incubated with lentivirus harboring a specific SNAP-25 RNAi sequence for $48-72 \mathrm{~h}$. SNAP-25, but not control, RNAi afforded complete blockade of PKM potentiation. $\boldsymbol{f}, \boldsymbol{g}$, Summary time course $(\boldsymbol{f})$ and bar graph $(\boldsymbol{g})$ showing that SNAP-25 (O), but not control ( $\mathbf{\square})$, RNAiabolished PKM potentiation of both peak and steady-state (SS) phases of NMDA currents $(n=4) .{ }^{* *} p<0.01$

monitored PKC potentiation of NMDA-elicited currents. The results thus far implicate a role for SNAP-25 in NMDAR insertion in neurons, but do not address the target of PKC phosphorylation. In neurons expressing WT SNAP-25, PKM potentiated NMDA currents by $\sim 80 \%$ relative to basal currents within 5-10 min of break-in (potentiation of the peak to $186 \pm 33 \%, p<$ 0.001 ; potentiation of steady state to $199 \pm 16 \%, p<0.001$; Fig. $5 a, b, d)$. Expression of SNAP-25(S187A) produced no significant change in basal NMDA-elicited currents neurons relative to WT SNAP-25 (WT vs S187A, peak, $926 \pm 211$ vs $635 \pm 254$ pA, $n=$ 

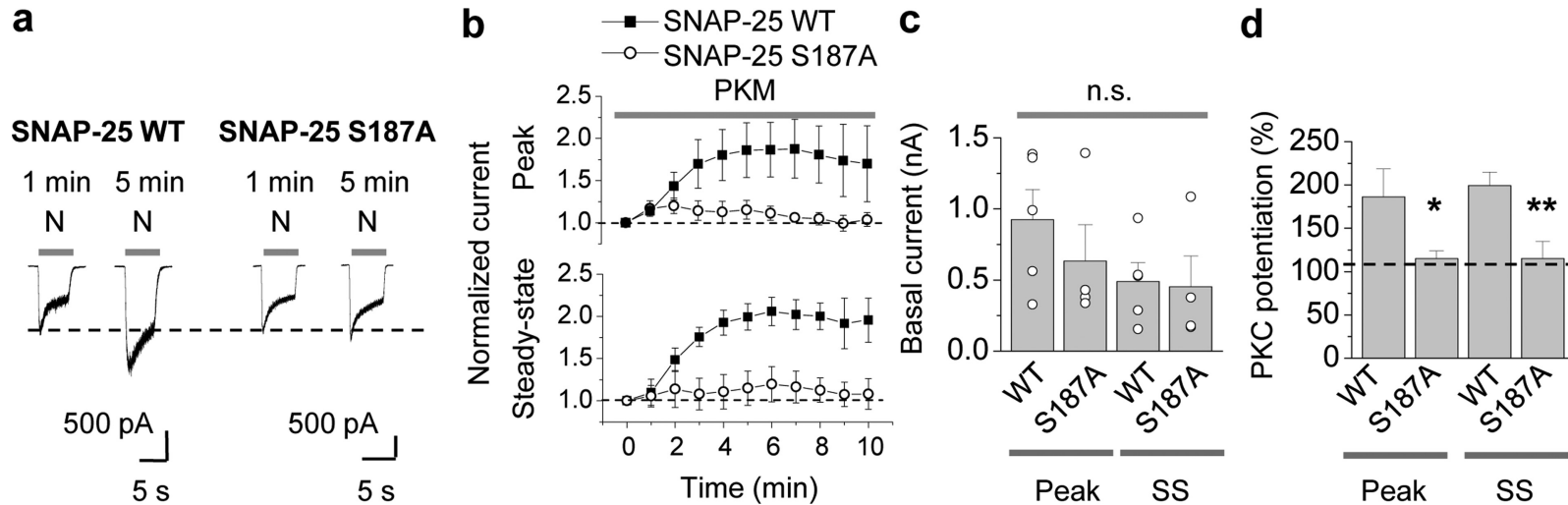

Figure 5. Phosphorylation of postsynaptic SNAP-25 at Ser187 is critical to PKC-induced insertion of NMDARs in neurons. $\boldsymbol{a}$, Representative traces showing PKC potentiation of NMDA responses in neurons expressing SNAP-25/pIRES2-EGFP. Whole-cell patch-clamp recordings were performed on hippocampal neurons (DIV 7-16) expressing SNAP-25 WT or S187A/pIRES2-EGFP, $1 \mathrm{~d}$ after transfection. PKM in the patch pipette potentiated NMDA currents expressing SNAP-25 WT (left). Mutant SNAP-25 (S187A) abolished PKC potentiation of NMDA currents (right). $\boldsymbol{b}$, Summary time course of PKM potentiation in cells expressing WT $(\square)$ versus mutant SNAP-25(S187A) (O). PKM potentiated the peak (top) and steady-state (SS, bottom) phases of NMDA-elicited currents $(n=$ 5 each). Current amplitudes were normalized to amplitudes of control responses recorded just after break-in (at 0 min). $\boldsymbol{c}, \boldsymbol{d}$, Expression of SNAP-25(S187A) did not alter the peak or steady-state phase of basal NMDA currents $(\boldsymbol{c})$, but abolished PKM-induced potentiation (d). n.S., not significant; ${ }^{*} p<0.05 ;{ }^{* *} p<0.02$.

$5, p>0.4 ;$ steady state, $488 \pm 133$ vs $452 \pm 216 \mathrm{pA}, n=5, p>0.8$ Fig. $5 c$ ), but completely blocked PKM-induced potentiation (WT vs S187A, peak, $186 \pm 33 \%$ vs $115 \pm 9 \%, n=5, p<0.05$; steady state, $199 \pm 16 \%$ vs $115 \pm 20 \%, n=5, p<0.01$; Fig. $5 a, c, d)$. In contrast, the phosphomimetic mutant SNAP-25 S187D did not detectably alter basal NMDA currents or PKM potentiation (supplemental Fig. 4, available at www.jneurosci.org as supplemental material). Due to the fact that transfection efficiencies in neurons are low $(\sim 10 \%)$ and that expression of WT and mutant SNAP-25 is sparse within a network, these results suggest that manipulations of postsynaptic SNAP-25 significantly impact on PKC potentiation of NMDA currents. Together, these findings indicate that PKC phosphorylation of serine residue 187 in SNAP-25 is critical to PKCinduced insertion of postsynaptic NMDARs in neurons.

Because overexpression of exogenous proteins may cause nonphysiological changes in neurons, we used an additional complementary strategy to examine a role for Ser 187 in SNAP-25 in PKC potentiation of NMDA currents. We applied peptides corresponding to the C-terminal region of SNAP-25 to acutely disrupt the interaction of endogenous SNAP-25 with its SNARE complex binding partners, syntaxin-1 and VAMP2. A SNAP-25 C-terminal peptide mimicking the BoNT A-cleavage fragment blocks vesicular exocytosis in chromaffin cells (Gutierrez et al., 1997). As a blocking peptide, we used an 11 aa peptide (corresponding to residues 182-192 of SNAP-25) that contains the nonphosphorylatable residue Ala in place of Ser at residue 187 flanked on either side by 5 aa (Fig. 6a). As a control, we used an 11 aa peptide with the same residue composition, but in a randomized order (scrambled). Dialysis of PKM (2 nM) with the scrambled peptide (control, $10 \mu \mathrm{M}$ ) via the patch pipette potentiated NMDA-elicited currents for a period of 5-10 min (peak, $128 \pm$ $11 \%$ of control, $n=7, p<0.05$, Fig. $6 b, c$ left; steady state, $115 \pm$ $10 \%$ of control, $n=7, p>0.1$, Fig. $6 b, c$ right). Application of chelerythrine $(1 \mu \mathrm{M})$, a selective inhibitor of the PKC catalytic subunit, reverted the potentiated NMDA responses to their original baseline values (Fig. 6b,c). In contrast, application of the blocking peptide completely abolished PKC potentiation of NMDA-elicited currents (peak, $96.3 \pm 5.0 \%$ of control; steady state, $94.8 \pm 2.8 \%$ of control; $n=7, p<0.05$ blocking vs scrambled peptide). $\mathrm{PKM}$ potentiation in the presence of the scrambled peptide was similar to that achieved in the absence of the peptide (data not illustrated).
To examine whether PKC-induced phosphorylation of SNAP-25 selectively regulates insertion of NMDARs or more generally regulates delivery of ligand-gated ion channels to the cell surface, we monitored the impact of PKM on $\alpha$-amino-3hydroxy-5-methyl-4-isoxazole propionic acid receptor (AMPAR)mediated currents in the same cell. After washout of NMDA and glycine, we recorded currents elicited by $1 \mathrm{~s}$ bath application of S-AMPA $(25 \mu \mathrm{M})$ to hippocampal neurons. Whereas PKM potentiated NMDA-elicited currents in the presence of scrambled peptide (Fig. 6b,c), it produced no detectable effect on AMPAelicited currents (blocking, $100.8 \pm 3.3 \%$ of control; scrambled, $92.2 \pm 3.8 \%$ of control; $p>0.05$ for all; Fig. $6 d-f$ right). These findings strongly suggest that postsynaptic assembly of the SNARE complex is required for PKC-dependent insertion of NMDARs (but not AMPARs) in hippocampal neurons.

\section{SNAP-25 mediates PKC potentiation in hippocampal slices}

The experiments thus far establish a role for SNAP-25 in PKCdependent insertion of NMDARs, but do not distinguish between synaptic and extrasynaptic NMDARs. To address this issue, we recorded isolated NMDA EPSCs (EPSCs) at mossy fiber (mf)-CA3 synapses of acute hippocampal slices from juvenile rats in the presence of CNQX and LY303070 (the active isomer of GYKI-53655) to block kainate receptors and AMPARs, and bicuculline to block $\mathrm{GABA}_{\mathrm{A}}$ Rs. The PKC-activating phorbol ester $\mathrm{PDBu}(1 \mu \mathrm{M})$, delivered via the recording pipette, did not detectably alter the paired-pulse ratio [PPR; control, PPR at $0 \mathrm{~min}$, $2.17 \pm 0.32$; PPR at 5-10 $\mathrm{min}, 2.31 \pm 0.28$; scrambled, PPR at 0 min, $2.50 \pm 0.39$, Fig. $7 a$; scrambled, PPR at 5-10 min, $2.76 \pm$ 0.48 (data not illustrated)], but markedly potentiated NMDA EPSCs in the absence (data not illustrated) or presence of the scrambled peptide (control, to $228.8 \pm 29.9 \%, n=9, p<0.01$; scrambled, to $235.4 \pm 42.6 \%, n=7, p<0.01$; Fig. $7 b, d$ ). As in the case of NMDA-elicited whole-cell currents recorded from dissociated neurons, application of the SNAP-25 blocking peptide via the patch pipette did not significantly affect basal NMDA transmission, assessed at $5 \mathrm{~min}$ after break-in (blocking peptide, $94.1 \pm 15 \%$; n.s. vs basal current in the absence of peptide), but greatly reduced PDBu potentiation of the NMDA EPSC at mfCA3 synapses (scrambled peptide, $235.4 \pm 42.6 \%$; blocking peptide, $105.7 \pm 8.2 \%, n=7, p<0.05$ vs scrambled peptide; Fig. $7 b, d)$. Additionally, dialysis of PKM $(1 \mu \mathrm{M})$ into the postsynaptic 
a

SNAP-25 1 MAEDADMRNELEEMQRRADQLADESLESTRRMLQLVEESKDAGIRTLVML 51 DEQGEQLERIEEGMDQINKDMKEAEKNLTDLGKFCGLCVCPCNKLKSSDA 101 YKKAWGNNQDGVVASQPARVVDEREQMAISGGFIRRVTNDARENEMDENL 151 EQVSGI IGNLRHMALDMGNE IDTQNRQIDRIMEKADSNKTRIDEANQRAT 201 KMLGSG

Ser187

Blocking MEKADANKTRI Scrambled KANAKTDEIRM

b NMDA

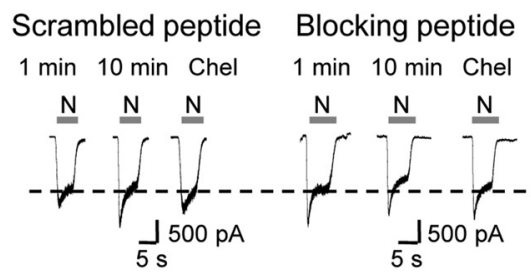

C

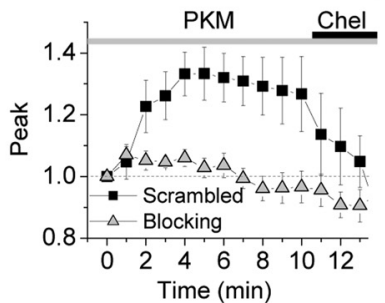

e

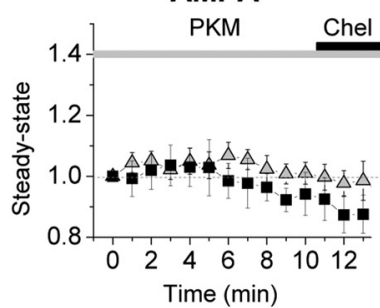

NMDA

\section{d}

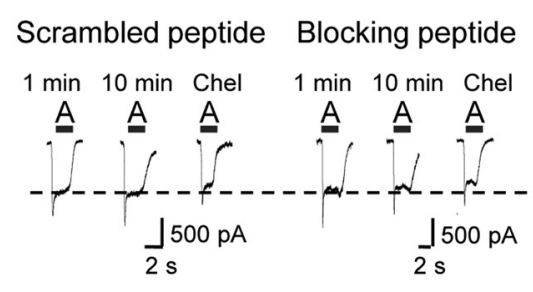

AMPA

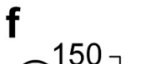

NMDA

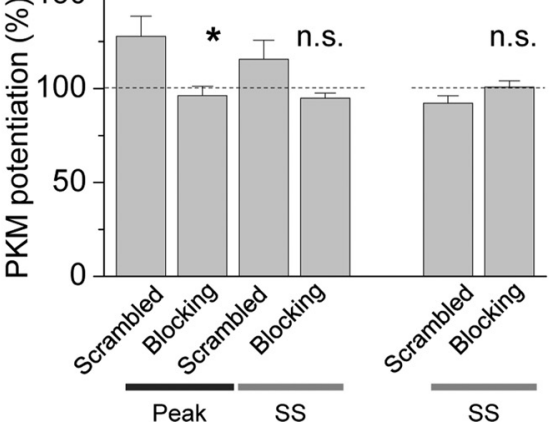

AMPA

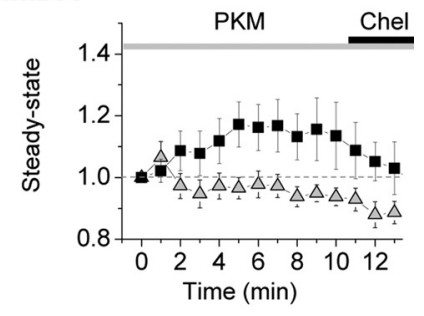<smiles>[Tl]</smiles>

Figure 6. Acute disruption of SNAP-25 interactions inhibits PKC-mediated insertion of NMDARs. $\boldsymbol{a}$, Peptides corresponding to 11 aa in the distal region of the C terminus of SNAP-25 were synthesized and coapplied with PKM via the patch pipette into neurons. The blocking peptide (MEKADANKTRI) contained the nonphosphorylatable residue Ala in place of Ser at residue 187 flanked on either side by 5 aa. The scrambled peptide (KANAKTDEIRM) had the same amino acid composition as the blocking peptide, but in a randomized order. All peptides were used at $10 \mu \mathrm{m}$ in the pipette. $\boldsymbol{b}-\boldsymbol{e}$, PKM potentiated NMDA but not AMPA currents recorded in the same neuron. $\boldsymbol{b}$, Representative traces showing that in the presence of the scrambled peptide, PKM potentiated NMDA-elicited currents in 5-10 min. The blocking peptide, containing an Ala in the center, completely abolished PKC insertion of NMDARs. c, Summary time course of those experiments described in $\boldsymbol{b}$. Whereas PKM potentiated NMDAR-mediated currents in the presence of the scrambled ( $\boldsymbol{\square})$ peptide, potentiation was abolished in the presence of the blocking peptide $(\boldsymbol{\Delta})$. $\boldsymbol{d}$, Representative traces of AMPA-elicited currents (S-AMPA, $25 \mu \mathrm{M}$ ) recorded in the same cell as in $\boldsymbol{b}$, following washout of NMDA and glycine, showing that AMPA responses were not potentiated by PKM in presence of either peptides. $\boldsymbol{e}$, Summary time course of those experiments described in $\boldsymbol{d}$.f, Summary bar graphs illustrating PKC potentiation of NMDA (left), but not AMPA (right), currents in hippocampal neurons at 9 min. $n=5-7$ for each peptide. Error bars represent SEM. ${ }^{*} p<0.05 ;{ }^{* *} p<0.01$; n.S., nonsignificant.

cell potentiated NMDA EPSCs to $364 \pm 76.5 \%$ of control by $5-10$ min after break-in (Fig. $7 c, d)$. Delivery of an anti-SNAP-25 antibody ( $\alpha$-SNAP-25) together with PKM greatly reduced the PKMinduced potentiation of NMDA EPSCs (from $364 \pm 76.5 \%, n=$ 8 , to $167.4 \pm 18.9 \% n=6, p<0.05$; Fig. $7 c, d)$. These findings demonstrate a postsynaptic action of SNAP-25 in PKC-mediated potentiation of synaptic NMDARs at mf-CA3 synapses.

\section{Activation of PKC promotes NMDAR surface expression in neurons}

The results thus far indicate that PKC potentiates postsynaptic NMDARs at hippocampal synapses, but do not address the mechanism by which the potentiation occurs. To address this issue, we examined the impact of PKC activation on surface ex- pression of NMDARs in neurons. Application of TPA in the presence of the phosphatase inhibitors OA (100 nM) and CsA ( $2 \mu \mathrm{M})$ (but not OA and CsA alone) enhanced the surface expression of NMDAR subunit NR1 in cortical neurons (DIV 7-10), as assessed by Western analysis of biotinylated cell-surface proteins (Fig. 8a,b). The increase in NR1 cell surface expression was blocked by Bis, indicating that it is PKC-mediated, and by BoNT $A$, indicating that it is SNARE-dependent $[p<0.05$ for TPA+OA+CsA, $n=4$ vs control (nontreated), $n=4$; Fig. $8 b, c]$. Total NR1 levels were not detectably altered (Fig. $8 b, c)$. In contrast, TPA in the presence of OA and CsA did not significantly enhance the surface expression of AMPARs as assessed by Western blotting for biotinylated surface GluR1 or GluR2 (GluR1: $\mathrm{OA}+\mathrm{CsA}$ vs $\mathrm{OA}+\mathrm{CsA}+\mathrm{TPA}, 104 \pm 16 \%$ vs $100 \pm 9 \%, n=3$, 
a

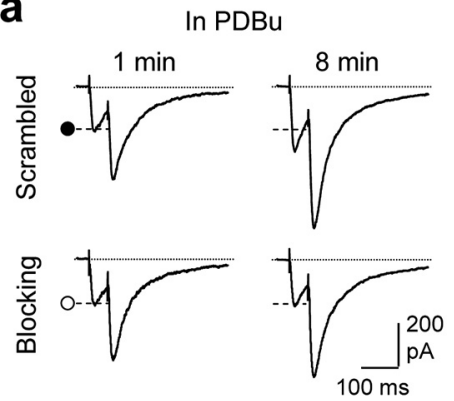

C

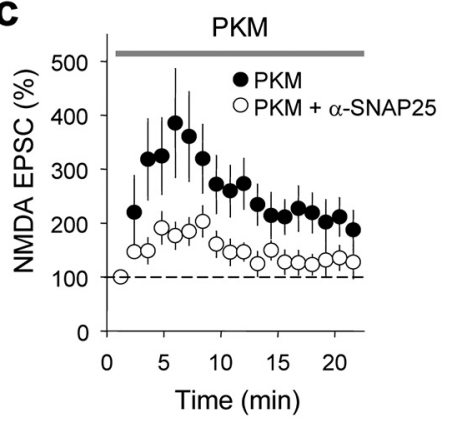

b

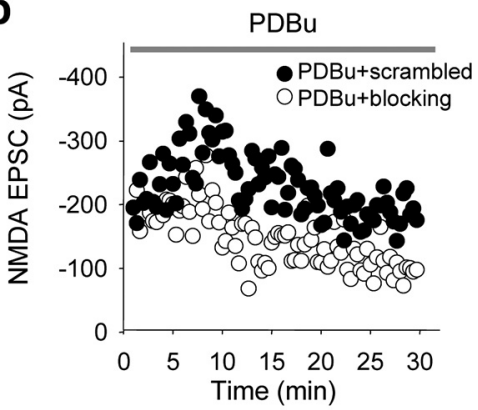

d

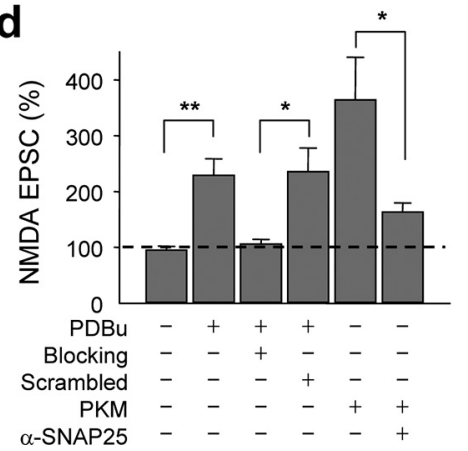

Figure 7. SNAP-25 is required for PKC-induced synaptic insertion of NMDARs in hippocampal slices. $\boldsymbol{a}-\boldsymbol{d}$, Synaptic NMDA currents (NMDA EPSCS) were recorded from CA3 pyramidal neurons in the presence of CNQX, LY303070, and picrotoxin (to block kainate receptors, AMPARs and $\mathrm{GABA}_{\mathrm{A}}$ receptors), and $1 \mathrm{~mm} \mathrm{Mg}^{2+}$ (to reduce $\mathrm{Mg}^{2+}$ block) at $V_{\mathrm{h}}=-40 \mathrm{mV}$. Mossy fibers were activated by paired-pulse electrical stimulation in the dentate gyrus. $\boldsymbol{a}, \boldsymbol{b}$, Representative traces $(\boldsymbol{a})$ and time course data $(\boldsymbol{b})$ showing that application of the PKC-activating phorbol ester PDBu (1 $\mu \mathrm{m}$, delivered via the recording pipette solution) potentiated NMDA EPSCs in the presence of the scrambled peptide (as in Fig. 6). Loading the postsynaptic cell with the SNAP-25 blocking peptide abolished PKC potentiation. $\boldsymbol{b}$, Representative time course data showing block of PKC potentiation by blocking peptide (○), but not by scrambled peptide (•). c, An anti-SNAP-25-antibody greatly reduced PKC-induced potentiation of NMDA EPSC. Summary time course showing that the catalytic subunit of PKC, PKM (1 $\mu \mathrm{m}$, delivered via the patch pipette), potentiated NMDA EPSC; a function-blocking anti-SNAP-25 antibody ( $\alpha$-SNAP-25) inhibited PKM potentiation. Each data point was the average of 6-8 experiments in which responses were binned every minute. $\boldsymbol{d}$, Summary of data in $\boldsymbol{a}-\boldsymbol{c}$. All data are expressed as means \pm SEMs of percent control response at break in. ${ }^{*} p<0.05$; ${ }^{* *} p<0.01$.

$p=0.84$; Fig. $8 d, e)$. These findings are consistent with a model whereby activation of PKC phosphorylates SNAP-25, which facilitates assembly of the SNARE complex and promotes insertion of new NMDA, but not AMPA, channels at the cell surface (Fig. $8 d$ ).

\section{Discussion}

The present study shows that PKC promotes NMDAR insertion of new NMDA channels in hippocampal neurons in culture and at mf-CA3 synapses via SNARE-dependent exocytosis. Although the functional target of $\mathrm{PKC}$ potentiation is well established, the molecular target of PKC is unclear. We further show that SNAP25 , a member of the SNARE family of vesicular fusion proteins, is a target of PKC phosphorylation functionally relevant to NMDAR trafficking. Several independent findings indicate that PKC-induced phosphorylation of SNAP-25 at Ser187 (and assembly of the SNARE complex) are critical to regulated delivery of NMDARs at the cell surface. First, dominant negative SNAP-25 reduced both basal and, in corroboration of Lan et al. (2001a), potentiated NMDA-elicited currents in oocytes. Second, RNAi-mediated depletion of SNAP-25 and BoNT A-mediated cleavage of SNAP-25 abolished PKM potentiation of NMDA currents in neurons. Third, overexpression of SNAP-25(Ser187Ala) abolished PKC potentiation of NMDA-elicited currents in oocytes and neurons. Fourth, acute disruption of SNAP-25 function by introduction of a blocking peptide corresponding to the $\mathrm{C}$ terminus of SNAP-25 phosphorylated at Ser187 attenuated

PKC-induced insertion of NMDARs in hippocampal neurons and slices. Fifth, introduction of a function-blocking SNAP-25 antibody into the postsynaptic cell markedly inhibited $\mathrm{PKC}$ potentiation of the NMDA EPSCs at CA3 synapses in acute hippocampal slices. Our findings that PKC promotes insertion of new NMDA channels at the postsynaptic side of mf-CA3 synapses in a SNAREdependent manner are consistent with findings of others (Kwon and Castillo, 2008). These findings, together with our finding that SNAP-25 is a target of PKC phosphorylation functionally relevant to NMDAR trafficking, provide a molecular mechanism by which activity induces LTP of NMDA-EPSCs at this synapse (Kwon and Castillo, 2008; Rebola et al., 2008). Whereas SNAP-25 is critical to regulated, PKC-dependent exocytosis of NMDARs, SNAP-23 mediates constitutive exocytosis of NMDAR transport packets in cortical neurons prior to synapse formation (Washburn et al., 2004) and constitutive cycling of NMDARs at CA1 synapses of cultured hippocampal slices (Suh et al., 2009).

SNAP-25 and syntaxin-1 (target or t-SNAREs) localize to the plasma membrane, where they dock with vesicular "v-SNAREs" such as VAMP2 and mediate fusion of cargo-loaded vesicles with the plasma membrane (Südhof and Rothman, 2009). PKC phosphorylation of SNAP-25 at Ser 187 promotes assembly of the SNARE complex and thereby facilitates recruitment of vesicles at the presynaptic membrane (Nagy et al., 2002). Based on findings in the present study, we propose a model whereby PKC phosphorylation of SNAP-25 at Ser187 also promotes insertion of NMDARs at the postsynaptic membrane (Fig. $8 f$ ). PKC also phosphorylates munc-18 (Wierda et al., 2007) and dynamin (Robinson et al., 1993), which regulate vesicular release at the presynaptic membrane. The finding of stable endocytic zones in regions lateral to the synapse/PSD of mature neurons (Blanpied et al., 2002; Rácz et al., 2004) indicates that receptors diffuse laterally from the synapse (where they are tightly anchored) to the perisynaptic region (where they are more mobile) to undergo endocytosis. Although not yet identified, exocytic zones may also localize lateral to PSDs. PKC phosphorylation of SNAP-25 could promote rapid insertion of new NMDA channels by recruiting NMDAR-loaded vesicles from recycling endosomes to the postsynaptic membrane by analogy to activity-dependent insertion of AMPARs (Park et al., 2004).

\section{SNARE-dependent glutamate receptor trafficking}

The specificity of PKC for SNAP-25 phosphorylation and NMDAR insertion is indicated by several findings. First, phosphorylation of Ser187, but not Ser28 and Thr29, is critical to PKC-dependent insertion of NMDARs in oocytes and neurons). Second, RNAi against SNAP-25 (but without effect on SNAP-23) abolishes PKC potentiation of NMDARs in neurons. Third, whereas PKC potentiates NR2A- and NR2B-containing NMDARs, it 
does not potentiate NR2C- or NR2Dcontaining receptors in Xenopus oocytes (Mori et al., 1993). Fourth, PKC potentiation is greater for NMDARs containing the short NR1 splice variants, NR1-3 and NR1-4, versus NMDARs containing long NR1 isoforms (Durand et al., 1992, 1993). Fifth, whereas PKM promotes postsynaptic SNAP-25-dependent insertion of NMDARs (present study) and SNAP-25dependent internalization of kainate receptors (Selak et al., 2009), it does not alter AMPAR trafficking (present study). These findings are consistent with findings that high-frequency stimulation (HFS) potentiates NMDA-, but not AMPA-, synaptic currents in a PKCdependent manner at mf-CA3 synapses (Kwon and Castillo, 2008). Whereas conventional PKM potentiates NMDA but not AMPA currents, atypical PKMzeta promotes surface expression of AMPARs but not NMDARs (Ling et al., 2006). The catalytic site of PKMzeta differs structurally from that of conventional and novel PKCs and would thus be expected to affect distinct molecular targets (Sacktor, personal communication). Our findings are also consistent with findings that NMDARs and AMPARs are transported to synaptic sites via distinct vesicles (Fong et al., 2002; Washbourne et al., 2002b) and are sorted via different intracellular pathways (Jeyifous et al., 2009) in hippocampal neurons. Whereas AMPARs undergo forward trafficking to the plasma membrane via the conventional somatic Golgi network, NMDARs traffic via a nonconventional secretory pathway involving CASK, SAP97 and dendritic Golgi outposts (Jeyifous et al., 2009) in close proximity to NMDARs and far from intracellular AMPARs.

It is well established that PKC acts via Src to regulate NMDAR function (Lu et al., 1999), and that genetic deletion of Src blocks PKM potentiation (Lu et al., 1999). PKC phosphorylates and activates Src (Lu et al., 1999), which in turn phosphorylates Tyr residues on the C-terminal tails of NR2 subunits, thereby increasing channel open probability and mean open time ( $\mathrm{Yu}$ et al., 1997). Although Fyn kinase-dependent phosphorylation of NR2B at Tyr1472 promotes constitutive delivery of synaptic NMDARs (Prybylowski et al., 2005), Src itself does not regulate NMDAR trafficking. A possible scenario is that whereas PKC acts via SNAP-25 to regulates NMDA trafficking (Lan et al., 2001a), it acts via Src to regulate intrinsic NMDA channel function. In that event, loss of either SNAP-25 or Src would be sufficient to attenuate $\mathrm{PKC}$ potentiation of NMDA currents.

We found that the phosphomimetic mutant SNAP25(S187D) did not detectably alter basal NMDA currents or PKC-mediated trafficking of NMDARs in neurons. Although phosphomimetic mutants may mimic the actions of phosphorylated proteins, in many cases they do not (Richard L. Huganir, Leonard K. Kaczmarek, personal communications). Given that an aspartate (or glutamate) residue approximates the negative charge, but is not structurally identical to, a phosphorylated serine, this is not surprising. Thus, our negative findings in the case of SNAP-25(S187D) argue neither for nor against a role of SNAP-25 S187 phosphorylation in PKC potentiation of NMDA currents in neurons. Our finding that neither the (S187A) and (S187D) mutants affects basal NMDA currents in neurons is consistent with findings that the SNAP-25 blocking peptide does not alter basal synaptic NMDA currents at CA3 synapses (present study; Kwon and Castillo, 2008) and that overexpression of the SNAP25(S187A) mutant does not detectably alter basal NMDA currents. Our finding in neurons is in contrast to our finding that the S187D mutant potentiates NMDA currents and partially occludes PKC potentiation in oocytes. There are several possible explanations for the differences in oocytes versus neurons. First, whereas the oocytes express a pure population of NR1/NR2A receptors, neurons express heterogeneous NMDARs. Second, synaptic receptors localize to postsynaptic densities together with scaffolding, adaptor and signaling proteins which modify their trafficking and function and are not necessarily expressed in oocytes. Third, whereas we bath-applied phorbol esters to oocytes, we delivered recombinant PKM via the patch pipette to neurons. Fourth, neurons may employ different mechanisms for constitutive versus regulated trafficking of NMDAs. The experiments in neurons are more physiologically relevant and more likely to reflect PKC-dependent regulation of NMDARs and 
synaptic plasticity involving NMDAR insertion at hippocampal synapses.

\section{Regulated NMDAR trafficking in synaptic plasticity}

Recent studies indicate that synaptic NMDAR number and/or subunit composition are also regulated in response to neuronal activity and sensory experience (Wenthold et al., 2003; PérezOtaño and Ehlers, 2005; Lau and Zukin, 2007), and that NMDARs serve not only as the trigger of synaptic plasticity, but may also contribute to the expression of LTP and LTD (Grosshans et al., 2002; Watt et al., 2004). In adult rats, HFS promotes PKCdependent, SNARE-dependent insertion of NMDARs at mf-CA3 synapses $\left(\mathrm{LTP}_{\mathrm{NMDAR}}\right)$ (Kwon and Castillo, 2008). Given that LTP-inducing protocols can induce SNAP-25 phosphorylation (Genoud et al., 1999), HFS may act via phosphorylation of SNAP-25 to promote insertion of NMDARs and elicit $\mathrm{LTP}_{\mathrm{NMDAR}}$. In addition to activation of NMDARs, stimulation of group I mGluR (mGluR1 and 5) can induce LTP of NMDA EPSCs (O'Connor et al., 1994; Jia et al., 1998; Kwon and Castillo, 2008). Moreover, activation of group I mGluRs promotes delivery of NMDA channels to the cell surface (Lan et al., 2001b). These observations raise the possibility that mGluRs could induce PKC-dependent phosphorylation of SNAP-25 and promote NMDAR insertion at the plasma membrane. Regulation of NMDAR trafficking provides a powerful mechanism for altering transmission efficacy and neuronal excitability during synaptic plasticity and remodeling.

\section{References}

Banker G, Goslin K (1988) Developments in neuronal cell culture. Nature 336:185-186.

Ben-Ari Y, Aniksztejn L, Bregestovski P (1992) Protein kinase C modulation of NMDA currents: an important link for LTP induction. Trends Neurosci 15:333-339.

Blanpied TA, Scott DB, Ehlers MD (2002) Dynamics and regulation of clathrin coats at specialized endocytic zones of dendrites and spines. Neuron 36:435-449.

Cheng D, Hoogenraad CC, Rush J, Ramm E, Schlager MA, Duong DM, Xu P, Wijayawardana SR, Hanfelt J, Nakagawa T, Sheng M, Peng J (2006) Relative and absolute quantification of postsynaptic density proteome isolated from rat forebrain and cerebellum. Mol Cell Proteomics 5:1158-1170.

Christensen JK, Paternain AV, Selak S, Ahring PK, Lerma J (2004) A mosaic of functional kainate receptors in hippocampal interneurons. J Neurosci 24:8986-8993.

Collingridge GL, Isaac JT, Wang YT (2004) Receptor trafficking and synaptic plasticity. Nat Rev Neurosci 5:952-962.

Durand GM, Gregor P, Zheng X, Bennett MV, Uhl GR, Zukin RS (1992) Cloning of an apparent splice variant of the rat $N$-methyl-D-aspartate receptor NMDAR1 with altered sensitivity to polyamines and activators of protein kinase C. Proc Natl Acad Sci U S A 89:9359-9363.

Durand GM, Bennett MV, Zukin RS (1993) Splice variants of the N-methylD-aspartate receptor NR1 identify domains involved in regulation by polyamines and protein kinase C. Proc Natl Acad Sci USA 90:6731-6735.

Follenzi A, Naldini L (2002) Generation of HIV-1 derived lentiviral vectors. Methods Enzymol 346:454-465.

Fong DK, Rao A, Crump FT, Craig AM (2002) Rapid synaptic remodeling by protein kinase C: reciprocal translocation of NMDA receptors and calcium/calmodulin-dependent kinase II. J Neurosci 22:2153-2164.

Genoud S, Pralong W, Riederer BM, Eder L, Catsicas S, Muller D (1999) Activity-dependent phosphorylation of SNAP-25 in hippocampal organotypic cultures. J Neurochem 72:1699-1706.

Grosshans DR, Clayton DA, Coultrap SJ, Browning MD (2002) LTP leads to rapid surface expression of NMDA but not AMPA receptors in adult rat CA1. Nat Neurosci 5:27-33.

Gutierrez LM, Viniegra S, Rueda J, Ferrer-Montiel AV, Canaves JM, Montal M (1997) A peptide that mimics the C-terminal sequence of SNAP-25 inhibits secretory vesicle docking in chromaffin cells. J Biol Chem 272:2634-2639.

Iwasaki S, Kataoka M, Sekiguchi M, Shimazaki Y, Sato K, Takahashi M (2000) Two distinct mechanisms underlie the stimulation of neurotransmitter release by phorbol esters in clonal rat pheochromocytoma PC12 cells. J Biochem 128:407-414.

Jahn R, Lang T, Südhof TC (2003) Membrane fusion. Cell 112:519-533.

Jeyifous O, Waites CL, Specht CG, Fujisawa S, Schubert M, Lin EI, Marshall J, Aoki C, de Silva T, Montgomery JM, Garner CC, Green WN (2009) SAP97 and CASK mediate sorting of NMDA receptors through a previously unknown secretory pathway. Nat Neurosci 12:1011-1019.

Jia Z, Lu Y, Henderson J, Taverna F, Romano C, Abramow-Newerly W, Wojtowicz JM, Roder J (1998) Selective abolition of the NMDA component of long-term potentiation in mice lacking mGluR5. Learn Mem 5:331-343.

Jiang M, Deng L, Chen G (2004) High Ca(2+)-phosphate transfection efficiency enables single neuron gene analysis. Gene Ther 11:1303-1311.

Jordan BA, Fernholz BD, Boussac M, Xu C, Grigorean G, Ziff EB, Neubert TA (2004) Identification and verification of novel rodent postsynaptic density proteins. Mol Cell Proteomics 3:857-871.

Kushner L, Lerma J, Zukin RS, Bennett MV (1988) Coexpression of $\mathrm{N}$-methyl-D-aspartate and phencyclidine receptors in Xenopus oocytes injected with rat brain mRNA. Proc Natl Acad Sci U S A 85:3250-3254.

Kwon HB, Castillo PE (2008) Long-term potentiation selectively expressed by NMDA receptors at hippocampal mossy fiber synapses. Neuron $57: 108-120$.

Lan JY, Skeberdis VA, Jover T, Grooms SY, Lin Y, Araneda RC, Zheng X, Bennett MV, Zukin RS (2001a) Protein kinase C modulates NMDA receptor trafficking and gating. Nat Neurosci 4:382-390.

Lan JY, Skeberdis VA, Jover T, Zheng X, Bennett MV, Zukin RS (2001b) Activation of metabotropic glutamate receptor 1 accelerates NMDA receptor trafficking. J Neurosci 21:6058-6068.

Lau CG, Zukin RS (2007) NMDA receptor trafficking in synaptic plasticity and neuropsychiatric disorders. Nat Rev Neurosci 8:413-426.

Leonard AS, Hell JW (1997) Cyclic AMP-dependent protein kinase and protein kinase $\mathrm{C}$ phosphorylate $\mathrm{N}$-methyl-D-aspartate receptors at different sites. J Biol Chem 272:12107-12115.

Liao GY, Wagner DA, Hsu MH, Leonard JP (2001) Evidence for direct protein kinase-C mediated modulation of $N$-methyl-D-aspartate receptor current. Mol Pharmacol 59:960-964.

Ling DS, Benardo LS, Sacktor TC (2006) Protein kinase Mzeta enhances excitatory synaptic transmission by increasing the number of active postsynaptic AMPA receptors. Hippocampus 16:443-452.

Lledo PM, Zhang X, Südhof TC, Malenka RC, Nicoll RA (1998) Postsynaptic membrane fusion and long-term potentiation. Science 279:399-403.

Lu W, Man H, Ju W, Trimble WS, MacDonald JF, Wang YT (2001) Activation of synaptic NMDA receptors induces membrane insertion of new AMPA receptors and LTP in cultured hippocampal neurons. Neuron 29:243-254.

Lu WY, Xiong ZG, Lei S, Orser BA, Dudek E, Browning MD, MacDonald JF (1999) G-protein-coupled receptors act via protein kinase C and Src to regulate NMDA receptors. Nat Neurosci 2:331-338.

Malenka RC, Bear MF (2004) LTP and LTD: an embarrassment of riches. Neuron 44:5-21.

Morgan A, Burgoyne RD, Barclay JW, Craig TJ, Prescott GR, Ciufo LF, Evans GJ, Graham ME (2005) Regulation of exocytosis by protein kinase C. Biochem Soc Trans 33:1341-1344.

Mori H, Yamakura T, Masaki H, Mishina M (1993) Involvement of the carboxyl-terminal region in modulation by TPA of the NMDA receptor channel. Neuroreport 4:519-522.

Nagy G, Matti U, Nehring RB, Binz T, Rettig J, Neher E, Sørensen JB (2002) Protein kinase $\mathrm{C}$-dependent phosphorylation of synaptosome-associated protein of $25 \mathrm{kDa}$ at Ser187 potentiates vesicle recruitment. J Neurosci 22:9278-9286.

O'Connor JJ, Rowan MJ, Anwyl R (1994) Long-lasting enhancement of NMDA receptor-mediated synaptic transmission by metabotropic glutamate receptor activation. Nature 367:557-559.

Okabe S, Miwa A, Okado H (1999) Alternative splicing of the C-terminal domain regulates cell surface expression of the NMDA receptor NR1 subunit. J Neurosci 19:7781-7792.

Park M, Penick EC, Edwards JG, Kauer JA, Ehlers MD (2004) Recycling endosomes supply AMPA receptors for LTP. Science 305:1972-1975. 
Pérez-Otaño I, Ehlers MD (2005) Homeostatic plasticity and NMDA receptor trafficking. Trends Neurosci 28:229-238.

Prybylowski K, Chang K, Sans N, Kan L, Vicini S, Wenthold RJ (2005) The synaptic localization of NR2B-containing NMDA receptors is controlled by interactions with PDZ proteins and AP-2. Neuron 47:845-857.

Rácz B, Blanpied TA, Ehlers MD, Weinberg RJ (2004) Lateral organization of endocytic machinery in dendritic spines. Nat Neurosci 7:917-918.

Rebola N, Lujan R, Cunha RA, Mulle C (2008) Adenosine A2A receptors are essential for long-term potentiation of NMDA-EPSCs at hippocampal mossy fiber synapses. Neuron 57:121-134.

Robinson PJ, Sontag JM, Liu JP, Fykse EM, Slaughter C, McMahon H, Südhof TC (1993) Dynamin GTPase regulated by protein kinase C phosphorylation in nerve terminals. Nature 365:163-166.

Scott DB, Blanpied TA, Swanson GT, Zhang C, Ehlers MD (2001) An NMDA receptor ER retention signal regulated by phosphorylation and alternative splicing. J Neurosci 21:3063-3072.

Scott DB, Blanpied TA, Ehlers MD (2003) Coordinated PKA and PKC phosphorylation suppresses RXR-mediated ER retention and regulates the surface delivery of NMDA receptors. Neuropharmacology 45:755767.

Selak S, Paternain AV, Aller MI, Picó E, Rivera R, Lerma J (2009) A role for SNAP25 in internalization of kainate receptors and synaptic plasticity. Neuron 63:357-371.

Shimazaki Y, Nishiki T, Omori A, Sekiguchi M, Kamata Y, KozakiS, Takahashi M (1996) Phosphorylation of 25-kDa synaptosome-associated protein. Possible involvement in protein kinase $\mathrm{C}$-mediated regulation of neurotransmitter release. J Biol Chem 271:14548-14553.

Südhof TC, Rothman JE (2009) Membrane fusion: grappling with SNARE and SM proteins. Science 323:474-477.

Suh Y, Terashima A, Petralia RS, Wenthold RJ, Isaac JTR, Roche PA, Roche KW (2009) The role of SNAP-23 in membrane targeting of postsynaptic glutamate receptors. Soc Neurosci Abstr 35:612.8.

Tingley WG, Ehlers MD, Kameyama K, Doherty C, Ptak JB, Riley CT, Huganir
RL (1997) Characterization of protein kinase A and protein kinase C phosphorylation of the N-methyl-D-aspartate receptor NR1 subunit using phosphorylation site-specific antibodies. J Biol Chem 272:5157-5166.

Wang H, Hu Y, Tsien JZ (2006) Molecular and systems mechanisms of memory consolidation and storage. Prog Neurobiol 79:123-135.

Washbourne P, Thompson PM, Carta M, Costa ET, Mathews JR, LopezBenditó G, Molnár Z, Becher MW, Valenzuela CF, Partridge LD, Wilson MC (2002a) Genetic ablation of the t-SNARE SNAP-25 distinguishes mechanisms of neuroexocytosis. Nat Neurosci 5:19-26.

Washbourne P, Bennett JE, McAllister AK (2002b) Rapid recruitment of NMDA receptor transport packets to nascent synapses. Nat Neurosci 5:751-759.

Washbourne P, Liu XB, Jones EG, McAllister AK (2004) Cycling of NMDA receptors during trafficking in neurons before synapse formation. J Neurosci 24:8253-8264.

Watt AJ, Sjöström PJ, Häusser M, Nelson SB, Turrigiano GG (2004) A proportional but slower NMDA potentiation follows AMPA potentiation in LTP. Nat Neurosci 7:518-524.

Wenthold RJ, Prybylowski K, Standley S, Sans N, Petralia RS (2003) Trafficking of NMDA receptors. Annu Rev Pharmacol Toxicol 43:335-358.

Wierda KD, Toonen RF, de Wit H, Brussaard AB, Verhage M (2007) Interdependence of PKC-dependent and PKC-independent pathways for presynaptic plasticity. Neuron 54:275-290.

Yao Y, Ferrer-Montiel AV, Montal M, Tsien RY (1999) Activation of storeoperated Ca2 + current in Xenopus oocytes requires SNAP-25 but not a diffusible messenger. Cell 98:475-485.

Yu XM, Askalan R, Keil GJ 2nd, Salter MW (1997) NMDA channel regulation by channel-associated protein tyrosine kinase Src. Science 275: 674-678.

Zheng X, Zhang L, Wang AP, Bennett MV, Zukin RS (1999) Protein kinase $\mathrm{C}$ potentiation of $\mathrm{N}$-methyl-D-aspartate receptor activity is not mediated by phosphorylation of $\mathrm{N}$-methyl-D-aspartate receptor subunits. Proc Natl Acad Sci U S A 96:15262-15267. 